\title{
The enabling technologies of industry 4.0: examining the seeds of the fourth industrial revolution
}

\section{Arianna Martinelli, ${ }^{1}$ Andrea Mina ${ }^{2,1}$ and Massimo Moggi ${ }^{3}$}

${ }^{1}$ Scuola Superiore Sant'Anna \& EMbeDS, Institute of Economics, Piazza Martiri della Libertà, 33, Pisa 56127, Italy. e-mail: arianna.martinelli@santannapisa.it, ${ }^{2}$ Scuola Superiore Sant'Anna \& EMbeDS, Institute of Economics, Piazza Martiri della Libertà, 33, 56127, Pisa, Italy; Centre for Business Research, University of Cambridge, Trumpington Street, Cambridge CB2 1AG, UK. e-mail: andrea.mina@santannapisa.it and ${ }^{3}$ Scuola Superiore Sant'Anna \& EMbeDS, Institute of Economics, and Westpole SpA, Piazza Martiri della Libertà, 33, Pisa 56127, Italy. e-mail: massimo.moggi@santannapisa.it

*Main author for correspondence.

\begin{abstract}
Technological revolutions mark profound transformations in socio-economic systems. They are associated with the development and diffusion of general-purpose technologies (GPTs) that display very high degrees of pervasiveness, dynamism and complementarity. This article provides an in-depth examination of the technologies underpinning the "factory of the future" as profiled by the Industry 4.0 paradigm. It contains an exploratory comparative analysis of the technological bases and the emergent patterns of development of Internet of Things, big data, cloud, robotics, artificial intelligence, and additive manufacturing. We qualify the "enabling" nature of these technologies. We then test whether, taken together and individually, they display the characteristics of generality, originality, and longevity associated with GPTs. Finally, we discuss key themes for future research on this topic from an industrial structural change perspective.
\end{abstract}

JEL classification: 033, 031, L01

\section{Introduction}

Technological revolutions are associated with the emergence of "constellation of innovations" that profoundly transforms the economy, and more broadly social systems (Freeman and Louçã, 2001; Perez, 2002, 2010). Examples of these technologies are water-powered energy and steam engine, which shaped the British Industrial Revolution, then electricity, automotive technologies and more recently information and communication technologies (ICTs). Observation of such cyclical revolutions has provided the basis for the development of a theory of long cycles in economic growth where spells of high and low growth are tied to the rise and fall of waves of technical change (Freeman and Louçã, 2001). The economic literature has also linked this uneven development path to the emergence of a specific class of technologies, general-purpose technologies (GPTs), characterized by pervasiveness, high dynamism and strong complementarities (Bresnahan and Trajtenberg, 1995; Jovanovic and Rousseau, 2005; Bresnahan, 2010). 
Understanding the effects of technological transformation requires opening up the "black box" of technology and explaining how, where and why they emerge and evolve (Rosenberg, 1982). Unique patterns of technical change develop through complex interactions of technical factors (e.g. characteristics of artifacts, their specifications and performance measures), the science base, and the broader institutional and economic context (Rosenberg, 1982, 1994). Dosi's (1982) concepts of technological paradigms and trajectories provide an ideal framework for the study of innovative activities encompassing cognitive, technical, institutional and economic dimensions. While technological paradigms characterize and bind the potentially unlimited research space of a technology, technological trajectories identify local, cumulative, and irreversible patterns of development through time (Dosi, 1988). This overarching framework is extremely useful to study emergent GPTs and integrate contextual elements of institutional analysis into this approach.

This is important because the identification, measurement and characterization of technological paradigms not only help us understand the knowledge bases of economic systems, but also make it possible to study the effects different paradigms may have for the patterns of industrial dynamics and competitiveness (Malerba and Orsenigo, 1996; Breschi et al., 2000). The potential for disruptive change specifically related to the development of GPTs has major implications for barriers to entry, market concentration, and the organization of value chains between incumbents and new entrants (Tushman and Anderson, 1986; Christensen, 1997). The expanding processes of digitalization and automation in manufacturing and services (Teece, 2018) make this kind of analysis all the more urgent because of their effects on productivity, wages and employment (Frey and Osborne, 2017; Acemoglu and Restrepo, 2017).

There is yet no consensus as to whether we are observing the onset of a Fourth Industrial Revolution and whether this coincides with the Industry 4.0 paradigm. They are not synonyms. Industry 4.0 is the qualification of the "factory of the future", shaped by policy interventions that have fostered the adoption of smart manufacturing technologies in Europe, and resulting from the convergence of a new wave of operational technologies with Internetdriven IT (Kagermann et al., 2013). This might be a fundamental component of a Fourth Industrial Revolution, but does not coincide with it because of its still relatively limited scale and scope. A similar difference exists, as Teece (2018) points out, between the notions of general purpose technology vis-à-vis enabling technology. Contrary to the concepts of technological paradigm (Dosi, 1982, 1988) and general purpose technology (Helpman, 1998), the concept of "enabling technology" has not been well defined in the academic literature because it has emerged in the policy arena to profile groups of technologies that can contribute to innovation and productivity growth in many sectors of the economy (Commission of the European Communities, 2009), and are therefore identified primarily as industrial policy targets (European Commission, 2017). Technologies are defined as "enabling” when they bear high transformative potential for the productive system in which they are deployed for a variety of uses (Teece, 2018). Paradigm changes and GPTs are much rarer than enabling technologies, but some enabling technologies can become GPTs and trigger paradigmatic change over time. This may happen, but has arguably not yet happened, with the diffusion, convergence and recombination of Industry 4.0 technologies associated with increased digitization, automation and interconnection.

This article provides an in-depth examination of the enabling technologies underpinning the "factory of the future" as profiled by the Industry 4.0 paradigm. It contains an exploratory comparative analysis of the technological bases and the emergent patterns of production and use of Internet of Things (IoT), big data, cloud, robotics, artificial intelligence and additive manufacturing. We specifically ask whether the emergent Industry 4.0 paradigm, and/or any of its individual component, can be qualified as a GPT.

Despite well-known limitations, patents are a powerful instrument to study of the structure and evolution of technological knowledge. We construct a dataset of more than 60,000 patent records to identify: (i) the growth of inventive activities and their distribution, (ii) sources and uses of technological knowledge in the six different fields; (iii) the interrelation of knowledge bases across fields. We then run econometric estimations to test whether Industry 4.0 technologies display the characteristics of GPTs. We integrate these quantitative analyses with a reflection on industrial applications as part of an agenda for future research in this area.

\section{The technological boundaries of "industry 4.0"}

Industry 4.0 is not a single technology but rather a cluster of different technologies that are de facto agglomerated together by technological leaders, pivotal users, system integrators and government policy makers. Figure 1 synthetizes 


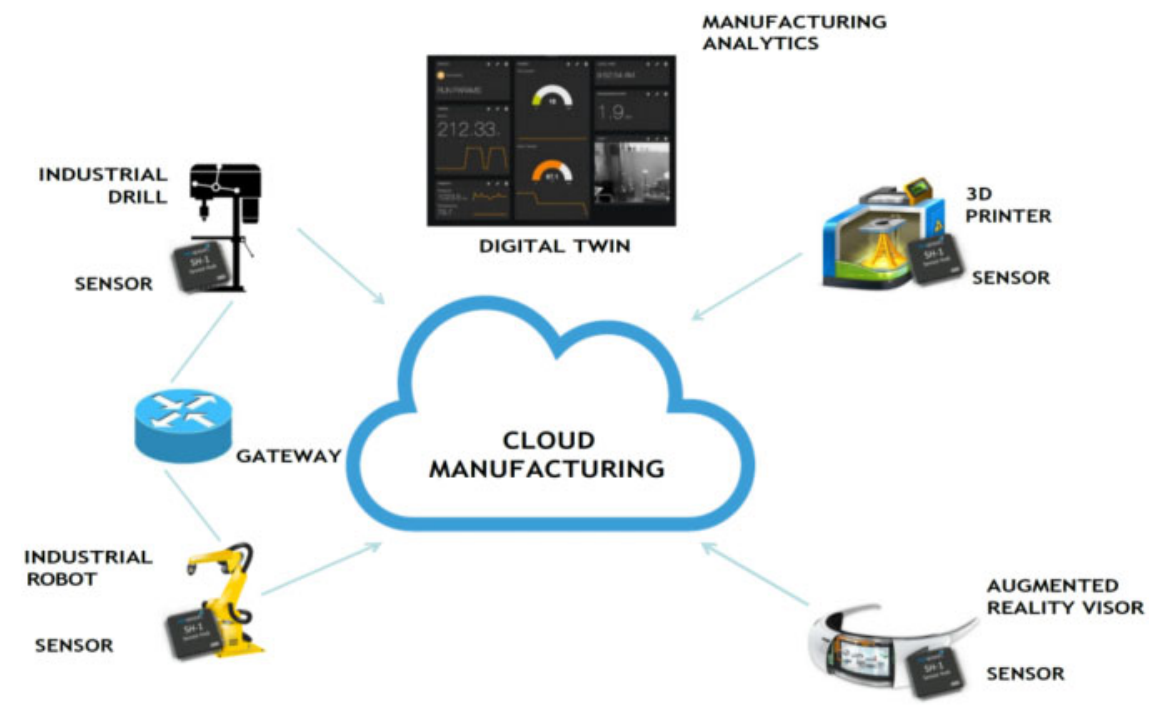

Figure 1. A graphical representation of industry 4.0.

the concept by illustrating the core technologies of Industry 4.0, with cloud manufacturing connecting industry devices through sensors and digital twins, and manufacturing execution systems (MES) keeping control of the whole factory streams through manufacturing analytics. It is clearly a complex architecture characterized by old technologies paired with new ones, all interconnected by cloud-based Internet.

In more detail, the technologies are:

- IoT. IoT encompasses devices with self-identification capabilities (localization, status diagnosis, data acquisition, processing, and implementation) that are connected via standard communication protocols. IoT technologies are used in I4.0 manufacturing applications, and in many others (housing and construction, automotive, environment, smart city, agriculture, health, etc.). In relation to Industry 4.0, IoT applications are specific to the so called "industrial Internet".

- Big Data/Industrial Analytics. This includes methods and tools to process large volumes of data for manufacturing, supply chain management and maintenance. The data can come from IoT systems connected to the productive layer (e.g. with sensors and associated equipment), or the exchange between IT systems for production and warehouse management. Specific applications in this area are machine learning tools for planning and forecasting, predictive maintenance, and simulation.

- Cloud Manufacturing. Cloud Manufacturing entails the application to manufacturing of cloud technologies, with widespread access, and easy and on-demand IT services-infrastructure, platform or application-to support production processes and supply chain management. Cloud manufacturing ranges from the virtualization of physical resources necessary for factory equipment, to application data and processes across platforms and execution-andcollaboration tools, hosted in the Cloud.

- Robotics. The robotics cluster includes SCARA, Articulated, Cartesian, Dual Arm and Co-bots (see section 2.4 for precise definitions) as different ways to automate production tasks. Advanced automation encompasses the latest developments in production systems with improved ability to interact with the environment, self-learning and automatic guidance, and the use of vision and pattern recognition.

- Artificial Intelligence (AI). It concerns the knowledge and techniques developed to make machines "intelligent," that is to say able to function appropriately also through foresight in their environment of the application. Industrial AI refers to the computer science-based technologies which, coupled with machine learning, are used to generate intelligent sensors, edge computing, and smart production systems.

- Additive Manufacturing, also known as 3D Printing. Additive Manufacturing finds application in the prototyping (to support the product development process, static simulation and wind tunnel, etc.), manufacturing (direct 
production of products), maintenance and repair and modelling phases. The US International Standard Organization defines the following seven categories of additive manufacturing processes: Binder Jetting, Directed Energy Deposition, Material Extrusion, Material Jetting, Powder Bed Fusion, Sheet Lamination and Photo polymerization (as per ISO TC 261, 2011).

We now provide a brief overview of each group of technologies.

\section{1 lot}

The concept of IoT was introduced in the 1980s at Carnegie Mellon where a modified Coke dispenser was made able to report its inventory, and to signal whether newly loaded drinks were cold through the Internet. IoT became popular in 1999 in the Auto-ID Center at MIT, with Radio-frequency identification (RFID) (Zhang et al., 2011; Chopra and Sodhi, 2007; Kubac et al., 2013; Liu and Chen, 2009). Several companies then introduced correlated concepts, including Olivetti, Xerox, IBM, and universities such as Carnegie Mellon and MIT itself, but it was Siemens who introduced a machine-to-machine (M2M) GMS connected system in 1995 (Benrachi-Maassam, 2012; Kima et al., 2017). Open source dynamics, as in many other IT segments, often pushed the development of IoT, as clearly illustrated by the adoption in 2003 of the (open source-based) JXYA standard as a universal peer-to-peer standard to connect electronic elements. After that, diffusion of the technology was boosted by the introduction of a low price, single board, electronic things controller, which originated in 2005 from the Interaction Design Institute Ivrea through the open-source electronics platform Arduino. Through this, IoT has progressively become a relevant offering for chip players as well as sensors producers, gateways hardware producers and software and machine developers for IoT platforms.

The basic disciplines at the roots of IoT are computer science, communication and information technology and electronics. The core technologies needed to build an IoT device are semiconductor technologies, internet, sensor technologies and more in general microelectromechanical systems. More specifically, within these core technologies, IoT devices incorporate Bluetooth technologies, low consumption battery technologies, laser technologies, smart cameras technologies, smart meters, and sensors for energy consumption. Within this heterogeneous assemble of different devices and solutions there are at least three technological clusters: devices, software platforms, and gateways and other networking elements. IoT technologies are still in an early stage of development and consequently characterized by an unstable competitive and technological environment. Technical challenges of this kind of environment include data exchange among large scale heterogeneous networks elements, integration and interaction adaptation of uncertain information, service adaptation in dynamic system environment.

There are structured data on R\&D spending specific to IoT, and we do not have any specific on the subsystem of Industrial IoT (IoT). Investments in these technologies are driven by private companies. IBM, Google, Samsung, SAP, Dell, Siemens, and Intel seem to be the companies investing more (IoT Analytics, 2015), but it is very difficult to identify a clear technology leader in both devices and platforms, also due to the vast number of different technologies and sectors involved. Interestingly, the growing interest of large companies in acquiring IoT capabilities seems to be driving a wave of consolidation in the industry, as signalled by the recent acquisition of Nest and CSR by Google and Qualcomm.

\subsection{Big data/industrial analytics}

A manufacturing analytic system starts out with a data acquisition system that can either be built-in by the original equipment manufacturer or a third-party provider. Using appropriate sensor assemblies, various signals such as vibration, pressure, temperature, etc. can be recorded. The types of signal and data acquisition parameters are determined by the application and the failure modes of the asset being monitored. Communication protocols, such as MT Connect and OLE-DB Process Control or OPC, can help users to acquire process or controller signals. Such data can provide context as to the type of action/function the machine was performing when sensor data was being collected. The aggregation of all information results in "Big Data" because of the volume of data collected, velocity by which data is being received and variety of data that are being collated. Such phenomenon requires new analytical approaches in place of standard statistical process control or other traditional techniques.

Several components are at play in this space: an integrated platform, predictive analytics, and visualization tools. The deployment platform is selected based on several factors such as the speed of computation, investment cost, and ease of deployment for scaling purposes and update. The actual processing or transformation of big data into useful information is performed by means of predictive analytics such as the tools found in the Watchdog Agent toolbox 
that has been developed by researchers at the National Science Foundation (NSF) Industry/University Research Cooperative Center (I/UCRC) for Intelligent Maintenance Systems (IMS) since 2001. There are also other commercial predictive analytic providers such as IBM, Hadoop, SAS, and SAP. The Watchdog Agent algorithms exemplify how this technology works. It can be categorized into four sections, namely: signal processing and feature extraction, health assessment, performance prediction and fault diagnosis (Yang et al., 2008). By using visualization tools, health information such as current condition, remaining useful life estimation, root cause, etc., can be effectively conveyed through radar charts, fault maps, risk charts, and even health degradation curves. The calculated health information can then be forwarded or made available to existing company management systems such as enterprise resource planning system (ERP), MES, supply chain management system, customer relation management system, and product lifecycle management system (PLM) to achieve overall enterprise control and optimization.

Big data analytics is the process of examining large and varied data sets to uncover hidden patterns, unknown correlations, market trends, customer preferences and other useful information that can help organizations make moreinformed business decisions. The term big data was first used to refer to increasing data volumes in the mid-1990s. In 2001, Doug Laney, then an analyst at consultancy Meta Group expanded the notion of big data to also include increases in the variety of data being generated by organizations and the velocity at which that data was being created and updated. Separately, the Hadoop distributed processing framework was launched as an Apache open source project in 2006, planting the seeds for a clustered platform built on top of commodity hardware and geared to run big data applications. Initially, as the Hadoop ecosystem took shape and started to mature, big data applications were primarily used by of large internet and e-commerce companies, such as Yahoo, Google, and Facebook, as well as analytics and marketing services providers. In ensuing years, though, big data analytics has increasingly been embraced by retailers, financial services firms, insurers, healthcare organizations, manufacturers, energy companies and other mainstream enterprises. While we do not have precise data on R\&D expenditure on manufacturing Big Data tools, the growth of patenting activities in this area indicates a rapid increase in commercial interest in this field (Ardito et al., 2018).

\subsection{Cloud manufacturing}

Cloud manufacturing is a new set of IT service delivery models. It can be divided into two categories. The first category is concerned with the deployment of manufacturing software on the Cloud, that is a "manufacturing version" of computing. The second category has a broader scope, cutting across production, management, design and engineering abilities in a manufacturing business. Unlike with computing and data storage, manufacturing involves physical equipment, monitors, materials, etc. In this kind of Cloud Manufacturing system, both material and non-material facilities are implemented on the Manufacturing Cloud to support the whole supply chain. In Cloud Manufacturing System, various manufacturing resources and abilities can be intelligently sensed and connected through the Internet, and automatically managed and controlled using IoT technologies (e.g. RFID, wired and wireless sensor network, and embedded system).

Several industrial players developed products in this space. In 2006 Amazon introduced its Elastic Compute Cloud. Microsoft Azure was announced as "Azure" in 2008 and released in 2010 as Windows Azure, before being renamed to Microsoft Azure in 2014 (for a time, Azure was on the TOP500 supercomputer list, before it dropped off it). In July 2010, Rackspace Hosting and NASA jointly launched an open-source cloud-software initiative known as OpenStack. The OpenStack project intended to help organizations offering cloud-computing services running on standard hardware. The early code came from NASA's Nebula platform as well as from Rackspace's Cloud Files platform. In 2011, IBM announced the IBM Smart Cloud framework to support Smarter Planet. Among the various components of the Smarter Computing foundation, cloud computing is a critical part. In 2012, Oracle announced the Oracle Cloud. While aspects of the Oracle Cloud are still in development, this cloud offering is poised to be the first to provide users with access to an integrated set of IT solutions, including the Applications (SaaS), Platform (PaaS), and Infrastructure (IaaS) layers. In April of 2008, Google released Google App Engine in beta. In 2012, Google Compute Engine was released in preview, before being rolled out into General Availability in $2013 .{ }^{1}$

1 For an extensive analysis of Cloud Manufacturing see: Adamson et al. (2013), Caldarelli et al. (2016), Wei et al. (2013), Wu et al. (2013, 2015), Tao et al. (2011, 2014), Putnik (2012), Hashem et al. (2014), Zhang and Chai (2010), and Majhi and Shial (2015). 
The field is a combination of applied research on virtualization, fast Internet, memory computing, and firewall technologies. Bloomberg and Red Monk report some figures on the R\&D expenditure of cloud computing companies. $^{2}$ From 2014 to 2017, in percentage terms over their total R\&D expenditure, IBM grew from 5\% to $6 \%$, Amazon from $8 \%$ to $12.5 \%$, Microsoft from $13 \%$ to $15 \%$ Google from $12.5 \%$ to $16 \%$ and Oracle from $13 \%$ to $16 \%$. In absolute terms, the available data show a substantial gap between the top-tier cloud providers (Amazon, Microsoft, and Google) and their competitors.

\subsection{Robotics}

Since the invention in 1954 of George Devol's first digitally operated and programmable robot, sold to General Motors in 1960, the advancements of robotics are well documented in the literature since the field is well established, and commercial and industrial robots are in widespread use. Robots are used in manufacturing, assembly and packing, transport, earth and space exploration, surgery, weaponry, laboratory research, and mass production of consumer and industrial goods. With recent advances in computer hardware and data management software, artificial representations of humans are also becoming widely spread, and artificial intelligence and machine learning are contributing to the development of modern flexible robots. Fundamental components of the robotic industry are sensors, actuators, power conversion units, manipulators, and software. Relative to other fields, we have much better data on $R \& D$ expenditures and markets. As far as R\&D expenditures are concerned, the three major spenders (KUKA, ABB, and YASKAVA) account for more than $70 \%$ of sales, and increasing investments. ${ }^{3}$

Industrial robots are typically classified in the following groups: SCARA, Articulated, Cartesian, Dual Arm and Co-bots. Selective Compliance Assembly Robot Arm (SCARA) is a type of robot which moves an "arm" on the horizontal plane and an outlet that can rise and fall in the vertical one. This type of robot was developed for high speed and repeatability in series assembly, such as Pick-and-Place from one place to another. An Articulated robot is a robot with rotary joints (e.g. a legged robot or an industrial robot), that can range from simple two-jointed structures to systems with 10 or more interacting joints. They are powered by a variety of means, including electric motors. A Delta robot is a type of parallel robot. It consists of three arms connected by universal joints to the base. The key feature of the design is the use of parallelograms in the arms, which maintain the orientation of the end device. Delta robots are usually used in picking and packaging in factories because they are fast enough to run more than 300 outlets per minute. Cartesian robots (or Gantry robot) are used for pick-and-place work, application of sealant, assembly operations, handling machine tools, and arc welding. They are robots whose arms have three prismatic joints, and axes are coincident with a Cartesian coordinator. Dual Arm robots are robots in which each of a pair of robotic arms has an anthropomorphic elbow, and configurations with six joints: there are three joints at the wrist that support the gripper (the end-effector) and the arm itself has three more joints to position the wrist at the desired location. Finally, Cobots or co-robots (from collaborative robot) are robots designed to physically interact with humans in a shared workspace. This is in contrast with other robots, designed to operate autonomously or with limited guidance, which is what most industrial robots were up until the 2010s.

To date, the world market for industrial robots is worth about $11 \mathrm{~B} \$$ (on a total of $27 \mathrm{~B} \$$ ) with steady, if not especially fast, growth rates (IFR, 2017). The market appears to be highly concentrated (in 2014 the top four manufacturers delivered robot units amounted to approximately $70 \%$ of the total robot units delivered worldwide in that year) and is signaling faster growth in easy-to-use collaborative robots, and a growing presence, through acquisitions, of new Chinese producers.

\subsection{Artificial intelligence}

Attempts to mechanize human intelligence have a relatively long history (Nilsson, 2010), but the development of modern AI-the term was coined back in 1954 by John McCarthy as the topic of a conference at Dartmouth-is intimately related to progress in computing technologies and to recent advancements in machine learning and predictive processes. AI includes various areas of research and it is often difficult to draw precise boundaries. Its core

2 https://redmonk.com/rstephens/2017/09/26/cloud_rd/; https://iot-analytics.com/industrial-technology-trends-industry-40patents-12x/; https://www.reddie.co.uk/2015/08/28/cloud-computing-patents-and-the-art-of-semantics/.

3 Figures have been obtained from the three companies' 2018 Annual Reports. 
components can however be identified with machine learning, deep learning, natural language processing platforms, predictive application programming interface (APIs), image recognition, and speech recognition.

Global R\&D spending in AI is fast increasing, both in the form of internal research in large tech firms' labs (i.e. Goole and Baidu), but also through VC-backed start-ups, often financed by corporate investments. Investments appear to be in the order of $\$ 25$ to $\$ 35$ billion (Bughin et al., 2018). Machine learning is the largest recipient of funds. Lee et al. (2018) note that the success of AI in industrial applications has so far been quite limited. However, industrial AI is fast improving as a systematic field of research, focused on developing, validating and deploying reliable machine learning algorithms for industrial applications (Bughin et al., 2017). Demand for is also expected to grow significantly over the next few years, with early industrial adopters clustered in the finance and banking, retail and manufacturing sectors. Industrial applications have so far been concentrated in autonomous robots, digital assistants, neurocomputers, machine monitoring and control systems, and expert systems such as healthcare decision and smart grid systems.

\subsection{Additive manufacturing}

In 1981, Hideo Kodama of Nagoya Municipal Industrial Research Institute published his account of a functional rapid prototyping system using photopolymers. A solid, printed model was built up in layers, each of which corresponded to a cross-sectional slice in the model. Then, the invention of stereolithography in 1984 lets designers create 3D models with digital data, which could then be used to create tangible objects. The key to stereolithography is a kind of acrylic-based material known as photopolymer. The process starts with a hit on a vat of liquid photopolymer with a UV laser beam, so that the light-exposed portion turns into a solid piece of plastic, and is then molded into the shape a 3D-model design. Interestingly, in that same decade (the 1980s) 3D printing crossed path with the opensource movement and this interaction continued over time until in 2005 Adrian Bowyer's RepRap Project launched an open-source initiative to create a 3D printer that could essentially build itself, or at least print most of its own parts. The first 3D printing machine became commercially viable in 2006, and this opened the door to on-demand manufacturing of industrial parts. 3D-printing start-up Objet (now merged with Stratasys) built a machine that could print in multiple materials, which allowed a single part to be fabricated in different versions and with different material properties. With the entry of MakerBot, an open-source DIY kit became available for makers to build their own 3D printers and products. With open source kits the barriers to entry for designers and inventors started to fall. While the price of $3 \mathrm{D}$ printers has fallen rapidly in recent years, the accuracy of $3 \mathrm{D}$ printing has significantly improved, and designers are no longer limited to printing with plastic.

The field of 3D printing has been growing rapidly for years. It has applications in many sectors as diverse as healthcare, aerospace, and parts replacement. This is an industry with large commitment to R\&D with 3-year average year (2014-2017) spend of \$309 million for all top six companies (Stratasys, Renishaw, 3 D Systems, Organovo, ExOne, and Arcam). Interestingly, Arcam has recently been acquired by General Electric for its multiple potential applications, ranging from aircraft components and medical equipment, to oil and gas equipment.

\section{The knowledge bases of $\mathbf{1 4 . 0}$ enabling technologies}

Having profiled the boundaries and building blocks of Industry 4.0, we now turn to an in-depth analysis of the knowledge bases of these technologies. We collected patent data for each enabling technology under examination. The main questions to be a concern the distribution of inventive efforts, their patterns of accumulation, and their relations and similarities.

\subsection{Data and sample construction}

Data were retrieved from the EPO-PATSTAT database (2019 Autumn Edition) but limitedly to granted United States Patent and Trademark Office (USPTO) patents filed between 1990 and 2014. Because of the relevance of the US market and the global nature of the actors involved, this choice does not introduce any significant home bias effect. We sampled patent records by following the search strategies documented in the literature and fully illustrated in Table 1, which also reports all the specific sources.

The final dataset includes 61,772 patents, of which $28,525(46.18 \%)$ related to Robotics, 13,919 (22.53\%) related to Artificial Intelligence, 7,932 (12.84\%) related to 3D Printing, 4,586 (7.42\%) related to IoT, 3,588 
Table 1 -Synopsis of the sampling strategy

\begin{tabular}{lc}
\hline Technology and references & CPC classes \\
\hline $\begin{array}{l}\text { Internet of Things (IoT) } \\
\text { Ardito } \text { et al. (2018) on the basis }\end{array}$ & $\begin{array}{c}\text { Derived from keywords: H04W4/70, } \\
\text { Y02B70/3*, Y02B90/24, } \\
\text { of UK IP Office, 2014. The }\end{array}$ \\
Internet of Things: A patent & Y02D70/21 \\
overview, UK Intellectual & \\
Property & \\
(IP) Office &
\end{tabular}

Cloud computing

Huang (2015), Dotsika (2017), IPO big data report (2014), Buyya et al. (2013)

Big Data

UK IP, 2014. Big Data \& Energy

Efficient Computing, UK

Intellectual Property (IP)

\section{Robotics}

UK IP Office, 2014. Eight great technologies: robotics and autonomous systems, UK Intellectual Property (IP) Office Available at. https://
Derived from keywords: G05B2219/ 32136

Conditional to keywords, from report: G06F 17/3* (does not exist anymore, replaced by G06F 16/*), G06F 19/7*-G06F19/1*G06F19/3* (do not exist anymore. Now, partially, G16Z 99* or G16B40/00, G16B50/00, G16H50/00, G16C20/70), G06Q 10/063*, G06Q 30/02*, G06F $17 /$ $50 *$ (does not exist anymore, now G06F 30/*), G06N/*

Derived from keywords: G06F16/

2465, G06F16/283, G06F2216/03

Derived from reports: B25J9/16*, B25J9/20, B25J9/0003, B25J11/ 0005, B25J11/0015, B60W30/*, Y10S901/*, G05D1/0088, G05D1/02*, G05D1/03, G05D2201/0207, G05D2201/ 0212

Derived from keywords: G05B2219/ 40*, G05D2201/0217, A61B34/ $3 *, \mathrm{~B} 25 \mathrm{~J} 9 / 0006, \mathrm{~B} 25 \mathrm{~J} 9 / 065$, G05D2201/0217

\section{Keywords}

internet of $\mid w 1$ thing $|w| *$, IIoT, Iol*T, ubicomp, ubiquitous computing, industrial internet, pervasive comput $|w| *$, ambient intelligence, smarter planet, smart dust, smart $\mid w 1$ devicelw $\mid *$, connected $\mid w 1$ devicelw $\left.\right|^{*}$, networked $\mid w 1$ devicelw $\rangle^{*}$, digital life, web of thing $|w|^{*}$, manchine to machine, M2M, smart meterlw ${ }^{*}$, smart grid $|w|^{*}$, smart homelw $\left.\right|^{*}$, internet of everything $|w|^{*}$

cloud comput $|w|^{*}$, cloud securit $|w|^{*}$, cloud technolog $|w|^{*}$, cloud serv $|w| *$, cloud process $|w|^{*}$, cloud softwarelw|*, cloud network $\mid w l^{*}$, cloud infrastructure $|w|^{*}$, cloud solution $|w|^{*}$, cloud system $|w|^{*}$, cloud data|w $\rangle^{*}$, cloud storagelw $\rangle^{*}$, cloud app $|w| *$, public cloud $|w| *$, private cloud $|w| *$, hybrid cloud $|w|^{*}$, service orient $|w|^{*}$, web servicelw*, utility orient $|w|^{*}$, utility comput $|w|^{*}$, cloud architectur|w $\left.|*| w\right|^{*$,$} -as-a-ser-$ vice, Aneka, InterCloud, multitenan $\mid w{ }^{*}$, OpenStack, Microsoft Azure, Cloudera, Amazon Web Services, AWS, Google Cloud Platform

big dat $|w|^{*}$, open dat $|w\rangle^{*}$, data warehouselw $\left.\right|^{*}$, hadoop, aster, datameer, fico blaze, vertica, platfora, splunk, mapreduce, crowdsourcing, data mining, data fusion, spark, biometrics, cassandra, nosql, behavioral analytics, business intelligence, HANA, hive, flume, kafka, elasticsearch

robot $|w\rangle^{*}$, cobot, self driving $\left.|w 3| w\right\rangle^{*}$ car $|w\rangle^{*}$, self driving $\mid w 3$ vehiclelw $\left.\right|^{*}$, self driving $\backslash w 3$ automobilelw $\left.\right|^{*}$, self driving $\mid w 3$ aircraft $|w|^{*}$, self driving $\mid w 3$ airplanelw $\left.\right|^{*}$, self driving $\mid w 3$ aeroplanelw $\mid *$, self driving $|w 3| w \mid *$ marine $|w| *$, driveless $|w 3| w\rangle^{*}$ carlw $\mid w$, driveless $\mid w 3$ vehiclelw $\rangle^{*}$, driveless $\mid w 3$ automobilelw $\rangle^{*}$, driveless Iw3 aircraft $|w| *$, driveless $\mid w 3$ airplanelw $\left.\right|^{*}$, driveless $\mid w 3$ aeroplanelw $\mid *$, driveless $\mid w 3$ $|w| *$ marine $|w| * \mid$, autonomous $|w 3| w \mid *$ carlw $\mid *$, autonomous $\mid w 3$ vehicle $|w| *$, autonomous $\mid w 3$ automobilelw $\mid *$, autonomous $\mid w 3$ aircraft $|w|^{*}$, autonomous $\mid w 3$ airplanelw|*, autonomous $\mid w 3$ aeroplanelw $\mid$, autonomous $\backslash w 3$ $|w| *$ marinelw|*, automated $\left.|w 3| w\right|^{*}$ carlw|", automated $\mid \mathrm{w} 3$ vehiclelw $\mid \mathrm{l}$, automated $\mid \mathrm{w} 3$ 
Table 1 Continued

\begin{tabular}{l} 
Technology and references \\
\hline 3D printing \\
UK IP Office, 2013.3D printing: \\
a patent overview, UK \\
Intellectual Property (IP) \\
Office Available at. https:// \\
www.gov.uk/government/pub \\
lications/3d-printing-a-patent- \\
overview
\end{tabular}

AI

Webb et al. (2018)
New class: B33Y: additive

manufacturing

Derived from report: B29C67/0051*

(does not exist anymore), B22F3/

1055, B22F 2003/1056, B22F

2003/1057, B22F 2003/1058,

B22F 2003/1059, B23K9/04*,

B23K10/027, B23K11/0013,

B23K15/0086, B23K20/1215,

B23K25/005, B23K26/34,

B23K26/342,

Additional, from keywords:

B29C64**, Y02P10/29*

Derived from WIPO report and key-

word search (intersection):

Y10S706/*, G06N20/*, G06N7/

02*, G06N7/005, G06N3/02,

G06T2207/20081, G06T2207/

20084, G06T3/4046, G06T9/002,

G05B13/027, G05B13/0275,

G05B13/028, G05B13/0285,

G05B13/029, G05B13/0295,

G10L15/16, Y10S128/924,

Y10S128/925, F02D41/1405,

B29C66/965, B29C66/966,

F03D7/046, F05B2270/707,

F05B2270/709, F16H2061/0081,

F16H2061/0084, G10K2210/

3038, G10L25/30, G10L25/33,

H04N21/4666
Keywords

automobile $|w\rangle^{*}$, automated $\mid w 3$ aircraft $|w| *$, automated $\mid w 3$ airplanelw $\mid *$, automated $\mid w 3$ aeroplane $|w| *$, automated $|w 3| w\rangle^{*}$ marinel $|w\rangle^{*}$, unmanned $|w 3| w|* c a r| w \mid *$, unmanned $\mid w 3$ vehiclelw|*, unmanned $\mid w 3$ automobile $|w| *$, unmanned $\mid w 3$ aircraft $|w|^{*}$, unmanned $\mid w 3$ airplanelw $\mid *$, unmanned $\mid w 3$ aeroplanelw $\left.\right|^{*}$, unmanned $|w 3| w \mid *$ marinelw|*

$3 \mathrm{D} \mid w 1$ print $|w|^{*}$, additive $\mid w 1$ manufactur $|w| *$, additive Iw1 fabrication, 3D Iw1 manufactorlwl*, 3D $\left.\right|_{w} 1$ fabrication, rapid $\mid w 1$ prototyp $|w| *$, rapid $\mid w 1$ manufact $|w|^{*}$, selective laser deposition $|w| *$, selective laser manufactur $|w| *$, laminate object manufactur $|w| *$, fuse deposition model $|w|^{*}$

artific $|w|^{*} \mid w 1$ intelligen $|w|^{*}$, computation $|w|^{*}$ $\mid w 1$ intelligen $|w|^{*}$, neural $\mid w 1$ network $|w|^{*}$, bayesian $\mid w 1$ network $|w|^{*}$, chatbot $|w|^{*}$, data $\mid w 1$ mining $|w|^{*}$, decision $\mid w 1$ model $|w|^{*}$, deep $\mid w 1$ learn|w $\left.\right|^{*}$, genetic $\mid w 1$ algorithm|w|*, inductive $\mid w 1$ logic $\mid w 1$ programm $|w|^{*}$, machine $\mid w 1$ learn $|w|^{*}$, natural $\mid w 1$ language $\mid w 1$ generation $|w|^{*}$, natural $\mid w 1$ language $\mid w 1$ process $|w|^{*}$, reinforcement $\mid w 1$ learn $|w| *$, $|w|$ "supervised $\mid w 1$ learn|w|*, $|w|$ "supervised $\mid w 1$ train $|w|^{*}$, swarm $\mid w 1$ intelligen $|w| *$, connectionis $|w|^{*}$, expert $\mid w 1$ system $|w|^{*}$, fuzzy $\mid w 1$ $\operatorname{logic}|w|^{*}$, transfer $\mid w 1$ learn $|w|^{*}$, learning $\mid w 3$ algorithm $|w|^{*}$, learing $\backslash \mathrm{w} 1$ model, support vector machine $|w|^{*}$, random forest $|w|^{*}$, decision treelw ${ }^{*}$, gradient model boosting, xgboost, adaboost, rankboost, logistic regression $|w|^{*}$, stochastic gradient descent, multilayer perceptron, latent semantic analysis, latent dirichelet allocation, multi agent system $|w|^{*}$, hidden markov model $|w|^{*}$

(5.81\%) related to Big Data, and 3,222 (5.22\%) related to Cloud. The bar chart in Figure 2 shows a significant increase over time in the total number of patents filed each year. Plotting the 3-year average growth rates of patent grants indicates a decade of positive growth from the beginning of the 2000s onwards, with the only interruption caused by the 2008 Financial Crisis.

Table 2 highlights differences in the number of patents and average growth rates over five periods (1990-1995; 1996-2000; 2001-2005; 2006-2010; 2011-2014) and across technologies. There are large variations across periods, but the data indicate strong growth for all technologies in the most recent period of the times series. 


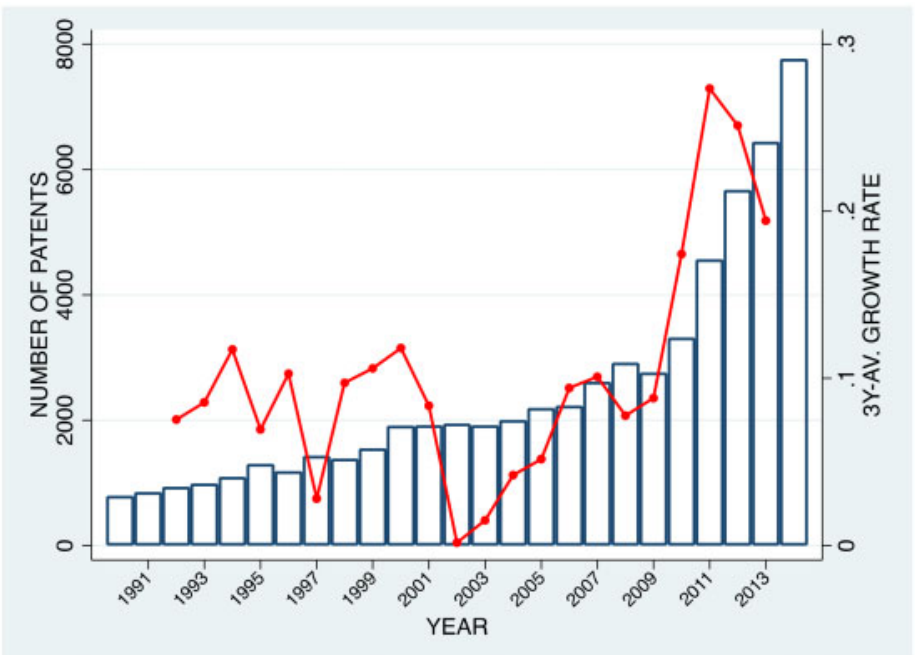

Figure 2. Time evolution and growth rate. Source: Authors' calculations.

Table 2- Number of patents and growth rates by technology

\begin{tabular}{|c|c|c|c|c|c|c|c|c|c|c|}
\hline & \multicolumn{2}{|l|}{ 1990-1995 } & \multicolumn{2}{|l|}{ 1996-2000 } & \multicolumn{2}{|l|}{ 2001-2005 } & \multicolumn{2}{|l|}{ 2006-2010 } & \multicolumn{2}{|l|}{ 2011-2014 } \\
\hline & $\begin{array}{l}\text { NUM } \\
\text { PATENTS }\end{array}$ & $\begin{array}{l}\text { AV. } \\
\text { GROWTH } \\
\text { RATE }(\%)\end{array}$ & $\begin{array}{l}\text { NUM } \\
\text { PATENTS }\end{array}$ & $\begin{array}{l}\text { AV. } \\
\text { GROWTH } \\
\text { RATE }(\%)\end{array}$ & $\begin{array}{l}\text { NUM } \\
\text { PATENTS }\end{array}$ & $\begin{array}{l}\text { AV. } \\
\text { GROWTH } \\
\text { RATE (\%) }\end{array}$ & $\begin{array}{l}\text { NUM } \\
\text { PATENTS }\end{array}$ & $\begin{array}{l}\text { AV. } \\
\text { GROWTH } \\
\text { RATE (\%) }\end{array}$ & $\begin{array}{l}\text { NUM } \\
\text { PATENTS }\end{array}$ & $\begin{array}{l}\text { AV. } \\
\text { GROWTH } \\
\text { RATE (\%) }\end{array}$ \\
\hline AI & 2415 & 13 & 2202 & 0 & 2010 & -2 & 2780 & 8 & 4512 & 24 \\
\hline BIG_DATA & 39 & 81 & 437 & 54 & 838 & 3 & 972 & 4 & 1302 & 21 \\
\hline CLOUD & 7 & 0 & 12 & 78 & 65 & 57 & 703 & 60 & 2435 & 26 \\
\hline IOT & 57 & 40 & 187 & 39 & 352 & 7 & 624 & 28 & 3366 & 54 \\
\hline PRINTING_3D & 580 & 26 & 1039 & 11 & 1721 & 6 & 1987 & 4 & 2605 & 22 \\
\hline ROBOTICS & 2887 & 5 & 3601 & 10 & 5013 & 4 & 6787 & 7 & 10,237 & 20 \\
\hline TOTAL & 4197 & 14 & 6288 & 11 & 9999 & 3 & 13,853 & 9 & 24,457 & 24 \\
\hline
\end{tabular}

\subsection{Geographical and organizational distribution of patents}

Patents carry essential information on who are the innovators and their geographical location. The strong technological opportunities that characterize emerging technologies are generally associated with low level of concentration of innovative activities, high entry rates and turbulence in the ranking of innovators (Malerba and Orsenigo, 1996a, 1996b, 1997; Breschi et al., 2000). Figure 3 displays the evolution of the concentration of the innovative activities in each enabling technology as measured by the C4 indicator and Herfindahl-Hirschman Index (HHI).

C4 measures the share of patents filed by the top four innovators; whereas, HHI index captures the dispersion of these shares. Figure 3 indicates a general reduction in concentration levels, according to standard theory. The most significant falls in the indices throughout the whole period concern Cloud, Big Data, and IoT. AI and Robotics display the steadiest patterns, while innovation in 3D printing becomes gradually less concentrated over time. Robotics and $3 \mathrm{D}$ printing are the technologies with the lowest concentration of innovation activities in the most recent period, which indicates the persistent presence of a high number of smaller-size players.

Figure 4 reports the evolution of the Spearman correlation for the ranking of the top 20 inventors. The Spearman correlation picks up the extent to which two variables have similar ranks. It is computed on every pair of consecutive years and varies between -1 and 1 (indicating an opposite and an identical ranking, respectively). Spearman correlation can therefore be used to capture the degree of technological turbulence in a field. Figure 4 shows some differences among the six technologies under examination. Big Data and IoT show consistently high stability over time. AI and Cloud displayed relatively low stability (i.e. higher turbulence) from 1995 to 2005, but their stability overall 


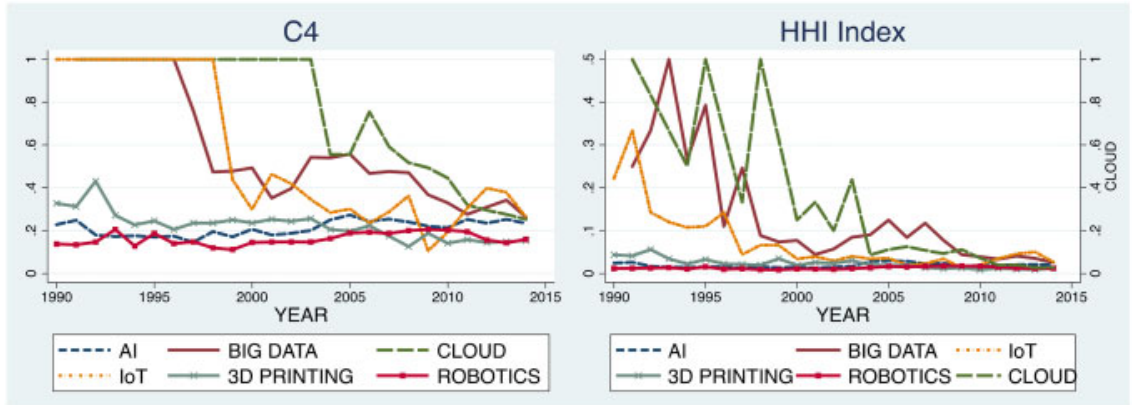

Figure 3. Evolution of innovative activities concentration. Source: Authors' calculations.

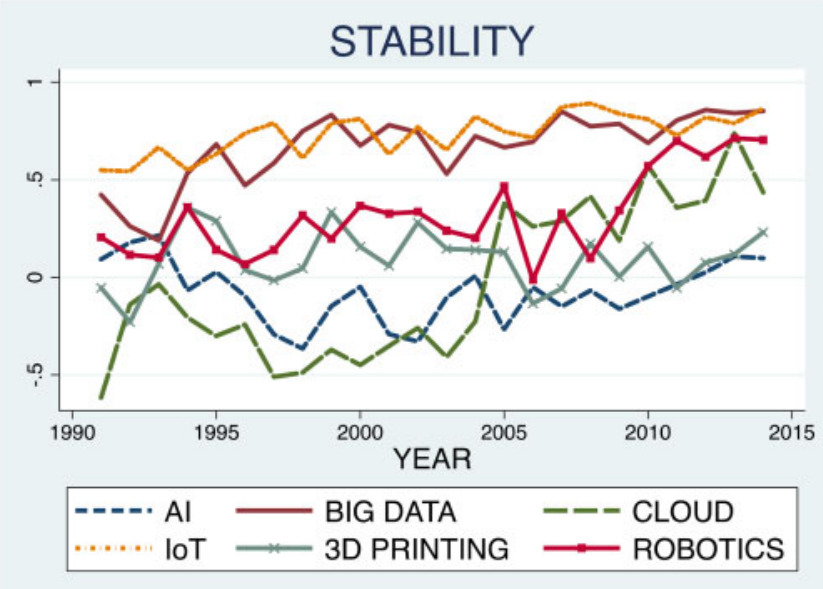

Figure 4. Evolution of the stability of innovative activities. Source: Authors calculations.

increased from 2005 onwards due to consolidation of technology leadership in these fields. 3D printing displays somewhat volatile patterns, with steady increases, indicating more stability in the group of top investors, over the last few years.

Besides these general trends, it is interesting to zoom into each technology and identify the top inventors. Table 3 reports the list of the top four inventors in each technology for the period 1990-1995 and the period 2010-2014. With the exception of IBM's performance in Big Data and AI, where the company is among the highest ranked players in both periods (and it reaches leadership in Cloud in the second period), the top positions are in the long run rather precarious. The field of AI saw Google, Microsoft and Amazon inherit the top ranks from Hitachi, Mitsubishi and Matsushita in the top four. Beside IBM, SAP, Oracle and Dell take leadership in Big Data. In Cloud, we see among the top performers in the first period the US Navy and the University of California (this hints at the role of mission-oriented and fundamental research, respectively, in this particular field). In the second period Microsoft, Google and Oracle take top positions after IBM. Intel takes leadership over competitors in IoT, followed by telecommunications companies LG, Ericsson and Qualcomm. In 3D printing, two universities (University of Texas and MIT) are overtaken by specialist 3D manufacturer Stratasys and orthopedics company Conformis, and large electronics conglomerates (GE and Siemens). Automotive companies Toyota and Ford take leadership in Robotics from robotics manufacturer Fanuc and Honda, followed by Google (this is the company's third appearance in the top innovators after AI and Cloud) and Intuitive Surgical (whose entry in the top four ranks complements Conformis' performance in 3D printing in indicating the growing role of medical applications).

From a geographical point of view, we observe in Table 3 a very high concentration of activities in the United States, with Japanese companies losing top positions in AI, Big Data, and IoT. Table 3 also reveals that technological 
Table 3 - Top Innovators over time and technology

\begin{tabular}{|c|c|c|c|c|c|c|}
\hline & \multicolumn{3}{|c|}{ Top innovators (1990-1995) } & \multicolumn{3}{|c|}{ Top innovators (2010-2014) } \\
\hline & Country & Company & Share $(\%)$ & Country & Company & Share $(\%)$ \\
\hline \multirow[t]{4}{*}{ AI } & JP & HITACHI & 4.97 & US & IBM & 9.50 \\
\hline & JP & MITSUBISHI & 4.75 & US & GOOGLE & 6.12 \\
\hline & US & IBM & 4.71 & US & MICROSOFT & 4.86 \\
\hline & JP & MATSUSHITA & 2.79 & US & AMAZON & 2.13 \\
\hline \multirow[t]{5}{*}{ BIG_DATA } & US & IBM & 47.37 & US & IBM & 13.86 \\
\hline & US & RCA & 10.53 & $\mathrm{DE}$ & SAP & 5.48 \\
\hline & $J P$ & FUJITSU & 5.26 & US & ORACLE & 3.76 \\
\hline & US & MICROSOFT & 5.26 & US & DELL & 3.76 \\
\hline & US & HONEYWELL & 5.26 & & & \\
\hline \multirow[t]{4}{*}{ CLOUD } & US & US NAVY & 25.00 & US & IBM & 13.82 \\
\hline & US & UNIVERSITY OF CALIFORNI & 25.00 & US & MICROSOFT & 5.71 \\
\hline & US & HEWLETT PACKARD & 25.00 & US & GOOGLE & 3.68 \\
\hline & $\mathrm{DE}$ & SIEMENS & 25.00 & US & ORACLE & 2.92 \\
\hline \multirow[t]{6}{*}{ IOT } & US & ACRES GAMING & 10.53 & US & INTEL & 12.34 \\
\hline & US & XEROX & 8.77 & KR & LG & 9.64 \\
\hline & US & TEXAS INSTRUMENTS & 7.02 & SE & ERICSSON & 5.99 \\
\hline & JP & $\mathrm{RICOH}$ & 5.26 & US & QUALCOMM & 4.01 \\
\hline & US & MOTOROLA & 5.26 & & & \\
\hline & US & QUALCOMM & 5.26 & & & \\
\hline \multirow[t]{4}{*}{ PRINTING_3D } & US & 3D SYSTEMS & 10.38 & US & STRATASYS & 4.38 \\
\hline & US & UNIVERSITY OF TEXAS & 3.85 & US & GENERAL ELECTRIC & 2.42 \\
\hline & SW & CIBA & 3.46 & US & CONFORMIS & 2.19 \\
\hline & US & MIT & 3.27 & $\mathrm{DE}$ & SIEMENS & 2.19 \\
\hline \multirow[t]{4}{*}{ ROBOTICS } & JP & FANUC & 4.82 & JP & TOYOTA & 5.21 \\
\hline & US & HONDA & 3.25 & US & FORD & 4.26 \\
\hline & US & MITSUBISHI & 2.29 & US & GOOGLE & 2.85 \\
\hline & US & HITACHI & 2.26 & US & A SURGICAL & 2.64 \\
\hline
\end{tabular}

leaders tend to overlap across the six enabling technologies. Strong complementarities in use could explain the tendency of these companies to develop technological capabilities that strand across all enabling technologies. The percentage of companies active in more than one technology in the period $1990-1995$ is $35 \%$ of the set, increasing to $41 \%$ in the period $2010-2014 .^{4}$

Different patterns of entry can trigger different technological dynamics. While we observe an increasing number of companies in each technology, it is important to distinguish whether they are really new entrants, or they just enter in a technology field while being active already in another technological space. An increase in the latter category can indicate patterns of consolidation between complementary technologies. Figure 5 shows that the share of entrants from another technology is overall increasing over time. Cloud and IoT attract the largest share of entrants from related technologies, Robotics the lowest, followed by AI. Note, however, that for AI this share increases over time.

\subsection{Sources and uses of technological knowledge}

The previous section focuses on technological relations based on patent citations (both backward and forward) and IPC classes. IPC classes are very informative about patents technological domain, but they cannot be straightforwardly related to industries. The two concepts can be tightly interrelated when they are both defined at a low level of granularity; however, numerous technologies cut across several industries. This section presents two specular exercises. First, we examine the industrial knowledge base used by the six enabling technologies to uncover common

4 Unreported graphs (available upon request) of the distribution of patent portfolio size by number of technologies show that a limited group of very large multi-technology firms drives this trend. 


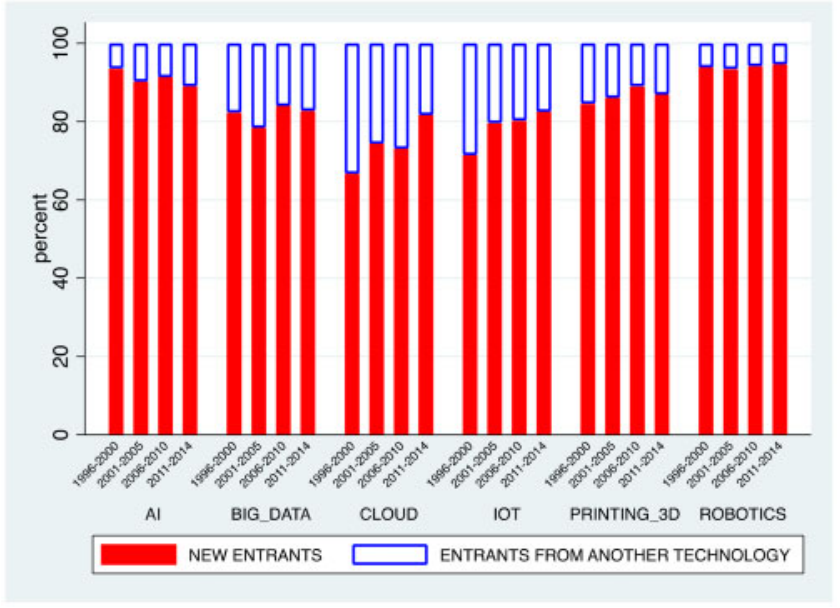

Figure 5. Patterns of entry over time. Source: Authors' calculations.

roots. Second, we examine the industrial applications of these enabling technologies to uncover joint applications. To carry out these two analyses we use data on the industrial classification of both the cited and citing patents of enabling technologies. Van Looy et al. (2015) provide a concordance table between IPC classes and 2-digit NACE (Rev. 2), which makes it possible to associate any patent to one or more 2-digit NACE (Rev. 2) codes. The EPO-PATSTAT Database provides the information we use in this analysis.

Table 4 shows backward citations over NACE classes and the C4 and HHI indices to evaluate their relative importance, thus indicating the industrial knowledge base behind each enabling technology. Table 4 reveals the presence of three patterns of use. AI, Big Data, Cloud and IoT have strong commonalities rooted in the manufacturing of computers, communication equipment, and office machinery. 3D Printings and Robotics display different industrial knowledge bases, including manufacturing of medical equipment and manufacturing of metal forming machinery and machine tools (both important for the two technologies) and more field-specific capabilities (e.g. Rubber and Plastics for 3D printing and Motor vehicles and Instruments for Robotics).

Another way to identify common patterns of development is measuring the similarity of technological domains used by each enabling technology. Cosine similarity, which has been extensively used to measure technological distance with patent data (Jaffe, 1986, 1989), can be fruitfully adapted to this context. Proximity between firms is typically measured by comparing vectors that represent firms' shares of the patents in each patent class. In this case, the similarity in industrial knowledge bases can be measured by comparing vectors of the shares of cited industrial technological domain for each enabling technology in each year. Figure 6 presents the evolution of the cosine similarity in the used industrial knowledge base over time and across technologies. AI, Big Data, and Cloud display remarkably stable patterns over time, which are rather similar to one another. This points to the presence of a long-term pattern of joint development between these three enabling technologies. IoT displays a falling trend (but always higher relative to 3D printing and Robotics) in the levels of similarity with AI, Big Data and Cloud. The second apparent trend is the increased convergence of $3 \mathrm{D}$ printing and Robotics.

Table 5 reports forward citations shares over NACE classes and the C4 and HHI indices to evaluate their relative importance. This information is useful to identify the industrial classes of application of inventions developed within an enabling technology. AI, Big Data, Cloud, and IoT appear to promote further technical advancement in the same industries, namely manufacturing of computer, communication equipment, and office machinery. Robotics also contributes to computer manufacturing, but shares with $3 \mathrm{D}$ printing medical device manufacturing as top field. The comparison of the $\mathrm{C} 4$ and $\mathrm{HHI}$ indicators presented in Tables 4 and 5 indicates that industrial application is much more concentrated than the industrial knowledge bases, and concentration of industrial applications is always highest for Big Data and Cloud.

Figure 7 reports the evolution of cosine similarity measures in the application industry. After an initial period of turbulence, as we saw for the technological knowledge bases the strongest similarities are between AI, Big Data, and 
Table 4 - Top used industrial knowledge base domains

\begin{tabular}{|c|c|c|c|c|c|}
\hline & & Using industrial knowledge domain & Share $(\%)$ & $\mathrm{C} 4$ & HHI \\
\hline \multirow[t]{4}{*}{ AI } & 26.2 & Manufacture of computers and peripheral equipment & 40 & 0.200 & 0.701 \\
\hline & 26.3 & Manufacture of Communication Equipment & 13 & & \\
\hline & 28.23 & $\begin{array}{l}\text { Manufacture of Office Machinery and Equipment (Except } \\
\text { Computers and Peripheral Equipment) }\end{array}$ & 12 & & \\
\hline & 62 & Computer Programming, Consultancy and Related Activities & 5 & & \\
\hline \multirow[t]{4}{*}{ BIG_DATA } & 26.2 & Manufacture of computers and peripheral equipment & 64 & 0.437 & 0.911 \\
\hline & 26.3 & Manufacture of Communication Equipment & 12 & & \\
\hline & 62 & Computer Programming, Consultancy and Related Activities & 10 & & \\
\hline & 28.23 & $\begin{array}{l}\text { Manufacture of Office Machinery and Equipment (Except } \\
\text { Computers and Peripheral Equipment) }\end{array}$ & 5 & & \\
\hline \multirow[t]{4}{*}{ CLOUD } & 26.2 & Manufacture of computers and peripheral equipment & 59 & 0.407 & 0.922 \\
\hline & 26.3 & Manufacture of Communication Equipment & 24 & & \\
\hline & 62 & Computer Programming, Consultancy and Related Activities & 6 & & \\
\hline & 28.23 & $\begin{array}{l}\text { Manufacture of Office Machinery and Equipment (Except } \\
\text { Computers and Peripheral Equipment) }\end{array}$ & 3 & & \\
\hline \multirow[t]{4}{*}{ IOT } & 26.3 & Manufacture of Communication Equipment & 50 & 0.291 & 0.784 \\
\hline & 26.2 & Manufacture of computers and peripheral equipment & 19 & & \\
\hline & 28.23 & $\begin{array}{l}\text { Manufacture of Office Machinery and Equipment (Except } \\
\text { Computers and Peripheral Equipment) }\end{array}$ & 6 & & \\
\hline & 26.5 & $\begin{array}{l}\text { Manufacture of Instruments and Appliances for Measuring, } \\
\text { Testing and Navigation; Watches and Clocks }\end{array}$ & 4 & & \\
\hline \multirow[t]{4}{*}{ PRINTING_3D } & 32.5 & Manufacture of medical and dental instruments and supplies & 25 & 0.097 & 0.495 \\
\hline & 22 & Manufacture of Rubber and Plastic Products & 11 & & \\
\hline & 26.1 & Manufacture of Electronic Components and Boards & 7 & & \\
\hline & 28.4 & Manufacture of Metal Forming Machinery and Machine Tools & 6 & & \\
\hline \multirow[t]{4}{*}{ ROBOTICS } & 32.5 & Manufacture of medical and dental instruments and supplies & 30 & 0.120 & 0.540 \\
\hline & 29.1 & Manufacture of Motor Vehicles & 9 & & \\
\hline & 26.5 & $\begin{array}{l}\text { Manufacture of Instruments and Appliances for Measuring, } \\
\text { Testing and Navigation; Watches and Clocks }\end{array}$ & 8 & & \\
\hline & 28.4 & Manufacture of Metal Forming Machinery and Machine Tools & 8 & & \\
\hline
\end{tabular}

Cloud. In this case, however, we also note similarity in industrial use between Cloud and IoT, which is consistent with qualitative evidence of joint deployment of Cloud and IoT. 3D Printing displays again patterns of complementarity in knowledge use with Robotics, with a marked decrease in the last 2 years of the period. Both 3D printing and Robotics appear to be diverging from all other technologies, and to find over time more specific areas of knowledge use.

\subsection{The interrelation of knowledge bases}

After examining the technological and industrial similarity of the six enabling technologies, we now assess whether and to what extent these technologies are interrelated, that is to say how these technologies cross-fertilize each-other, by using cross-citations between patents. While we based our previous analysis on citations made and received from the universe of USPTO granted patents, in this section, we examine "internal" citations within patent sets. Figure 8 reports for each enabling technology the share of citations made to patents related to a focal enabling technology. The first category is always the share of "self-citations," that is, citations between patents in the same enabling technology. Figure 9 reports similar graphs illustrating the shares of citations received by the enabling technologies. The comparison of the two figures provides information on the evolution of the reciprocal positions of these technologies in an interrelated technology system.

AI, 3D Printing, and Robotics seem to be the technologies characterized by more independent development, with shares of self-citations constantly well above the $70 \%$ mark for both backward and forward citations. Big-Data, Cloud, and IoT display more varied dynamics, indicating a more integrated position in the technological system. Big 

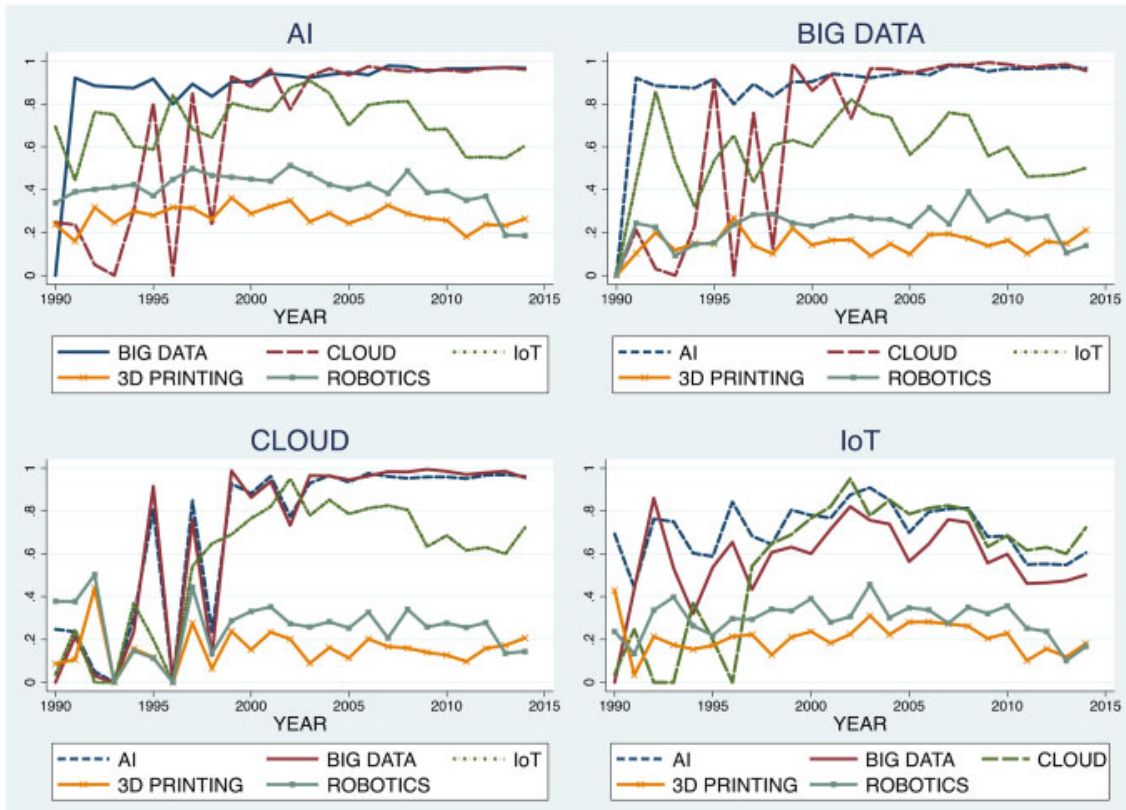

3D PRINTING

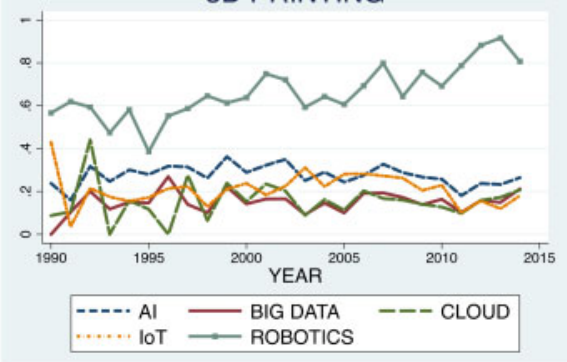

ROBOTICS

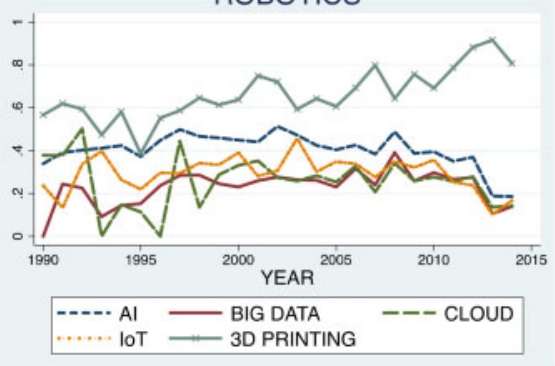

Figure 6. Similarity of used industrial knowledge base by technology.

data tend to display patterns of cross-fertilizing above all with AI. Cloud displays a variety of cross-technology citations, but a field becomes more self-referential in the most recent years, when within-field citations account for approximately $80 \%$ of total citation. IoT follows a similar pattern to Cloud with increased within-technology citations over time, with the exception of the last two years, which display more variety.

\section{Are industry 4.0 technologies new "general purpose" technologies?}

In this section we evaluate the extent to which the six enabling technologies can be considered as general purpose technologies (GPTs). Bresnahan and Trajtenberg (1995) define GPTs as technologies characterized by (i) pervasiveness (i.e. with a broad range of possible application sectors), (ii) high technological dynamism (i.e. significant potential for increasing efficiency), and (iii) the ability to generate complementarities (i.e. their adoption stimulates rapid technical progress in the application sectors). How do our six enabling technologies fare against these three criteria? To empirically address this question, we follow the approach designed by Moser and Nicholas (2004) in their study of Electricity as a GPT. We use regression analysis to examine how Industry 4.0 patents score on three patent indicators-generality, originality, and longevity—generally associated with GPTs, as compared to similar technologies.

The generality index (GENERALITY) captures the range of later generations of inventions that have been promoted by a patent, by measuring the breath of technological classes citing that patent (Trajtenberg et al., 1997). This indicator is based on the HHI index and relies on information about the number of forward citations and their 
Table 5 -Top sourced industrial knowledge base domains

\begin{tabular}{|c|c|c|c|c|c|}
\hline & & USED INDUSTRIAL KNOWLEDGE DOMAIN & Share & $\mathrm{C} 4$ & HHI \\
\hline \multirow[t]{4}{*}{ AI } & 26.2 & Manufacture of computers and peripheral equipment & $36 \%$ & 0.179 & 0.692 \\
\hline & 26.3 & Manufacture of Communication Equipment & $12 \%$ & & \\
\hline & 28.23 & $\begin{array}{l}\text { Manufacture of Office Machinery and Equipment (Except } \\
\text { Computers and Peripheral Equipment) }\end{array}$ & $12 \%$ & & \\
\hline & 62 & Computer Programming, Consultancy and Related Activities & $8 \%$ & & \\
\hline \multirow[t]{4}{*}{ BIG_DATA } & 26.2 & Manufacture of computers and peripheral equipment & $67 \%$ & 0.479 & 0.954 \\
\hline & 62 & Computer Programming, Consultancy and Related Activities & $13 \%$ & & \\
\hline & 26.3 & Manufacture of Communication Equipment & $12 \%$ & & \\
\hline & 28.23 & $\begin{array}{l}\text { Manufacture of Office Machinery and Equipment (Except } \\
\text { Computers and Peripheral Equipment) }\end{array}$ & $4 \%$ & & \\
\hline \multirow[t]{4}{*}{ CLOUD } & 26.2 & Manufacture of computers and peripheral equipment & $44 \%$ & 0.341 & 0.906 \\
\hline & 26.3 & Manufacture of Communication Equipment & $38 \%$ & & \\
\hline & 62 & Computer Programming, Consultancy and Related Activities & $5 \%$ & & \\
\hline & 28.23 & $\begin{array}{l}\text { Manufacture of Office Machinery and Equipment (Except } \\
\text { Computers and Peripheral Equipment) }\end{array}$ & $4 \%$ & & \\
\hline \multirow[t]{4}{*}{ IOT } & 26.3 & Manufacture of Communication Equipment & $35 \%$ & 0.194 & 0.763 \\
\hline & 26.2 & Manufacture of computers and peripheral equipment & $22 \%$ & & \\
\hline & 28.23 & $\begin{array}{l}\text { Manufacture of Office Machinery and Equipment (Except } \\
\text { Computers and Peripheral Equipment) }\end{array}$ & $10 \%$ & & \\
\hline & 32 & Other Manufacturing & $10 \%$ & & \\
\hline \multirow[t]{4}{*}{ PRINTING_3D } & 32.5 & Manufacture of medical and dental instruments and supplies & $21 \%$ & 0.096 & 0.542 \\
\hline & 22 & Manufacture of Rubber and Plastic Products & $15 \%$ & & \\
\hline & 28.9 & Manufacture of Other Special-Purpose Machinery & $9 \%$ & & \\
\hline & 26.1 & Manufacture of Electronic Components and Boards & $8 \%$ & & \\
\hline \multirow[t]{4}{*}{ ROBOTICS } & 32.5 & Manufacture of medical and dental instruments and supplies & $28 \%$ & 0.111 & 0.502 \\
\hline & 26.2 & Manufacture of computers and peripheral equipment & $9 \%$ & & \\
\hline & 29.1 & Manufacture of Motor Vehicles & $7 \%$ & & \\
\hline & 26.5 & $\begin{array}{l}\text { Manufacture of Instruments and Appliances for Measuring, } \\
\text { Testing and Navigation; Watches and Clocks }\end{array}$ & $7 \%$ & & \\
\hline
\end{tabular}

distribution across International Patent Classification (IPC) technology classes. It ranges from 0 (when all the citations received from the patents are from the same technological classes) to 1 (when all the citations are equally spread across different technological classes). The larger the value of the index, the more technologically widespread the effect of a patent, in line with the definition of a GPT (Hall and Trajtenberg, 2004).

The originality index (ORIGINALITY) is similar to the generality indicator, but it focuses on backward citations by measuring the range of technological classes that are cited by the patent (Trajtenberg et al., 1997). The more diverse the technological base upon which a patent is built, the more potential for novel recombination. This indicator is also based on the HHI index and relies on information about the number of backward citations and their distribution across IPC classes. It ranges from 0 (when all the citations made by a patent are from the same technological classes) to 1 (when all the citations are equally spread across different technological classes). High originality captures the high technological dynamism that is typical of GPTs (Trajtenberg et al., 1997; Moser and Nicholas, 2004). Finally, patent longevity measures the speed of obsolesce of a specific patent. As it was found for electricity (Moser and Nicholas, 2004), GPTs are expected to have lasting effects on subsequent technological development and therefore to become obsolete less fast. Following Moser and Nicholas (2004), we measure patent longevity as the average lag (in years) between the year of patent grant and the year of the latest forward citation (AV_LONGEVITY). ${ }^{5}$ All three indicators have been calculated using the EPO-PATSTAT Database (Autumn 2019 version).

5 Note that Moser and Nicholas (2004) measure longevity also as the maximum lag (in years) between the year of patent grant and the year of the latest forward citation. While we present the result using the average longevity, we also run the analysis using the maximum longevity and the results are qualitatively (i.e. sign and significance) similar. 


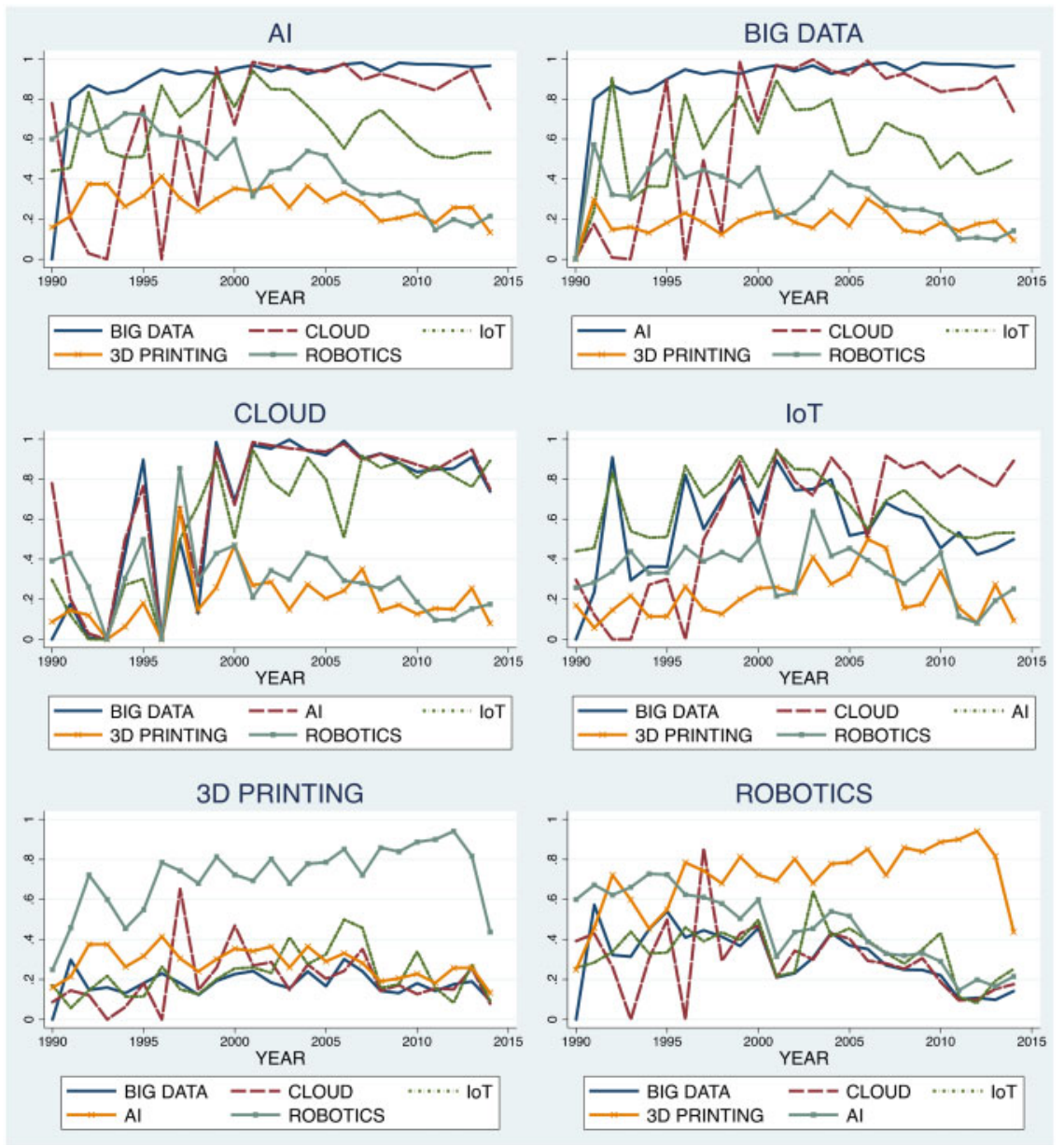

Figure 7. Similarity of using industrial knowledge base by technology.

To assess the extent to which the technologies included in the Industry 4.0 paradigms are GPTs, we compare our set to patents to a control group. We select the control patents by randomly matching each patent in our set to up to five USPTO granted patents (without replacement) that are not related to one of the technologies under examination (and are not part of the same DOCDB family). ${ }^{6}$ The matching procedure ensures that the joint distribution of primary technological class, grant years, assignee type is balanced between the two samples. Note that this control set does not provide an estimate of the exact counterfactual outcome but rather an estimate of the "average outcome" in a set of patents with similar characteristics. ${ }^{7}$ To complete the analysis, we also include two other variables that are the number of citations received by the patents in the first 5 years after the granting (FORW_CIT_5Y) and the number of IPC-classes listed in the patent document (NUM_IPC_CLASS). ${ }^{8}$

Table 6 reports the results from nonparametric Mann-Whitney rank-sum tests of the null hypothesis that the median characteristics of patents related to Industry 4.0 are identical to the control sample. These tests show that

6 The matching of at least one control patent was successful for 54,109 patents out of 61,322 starting set (88.2\%), with the matching of 5 controls $87.6 \%$ of all the starting set.

7 See Appendix A for the descriptive statistics of the sample.

8 See Appendix A for a summary table of the variables used. 

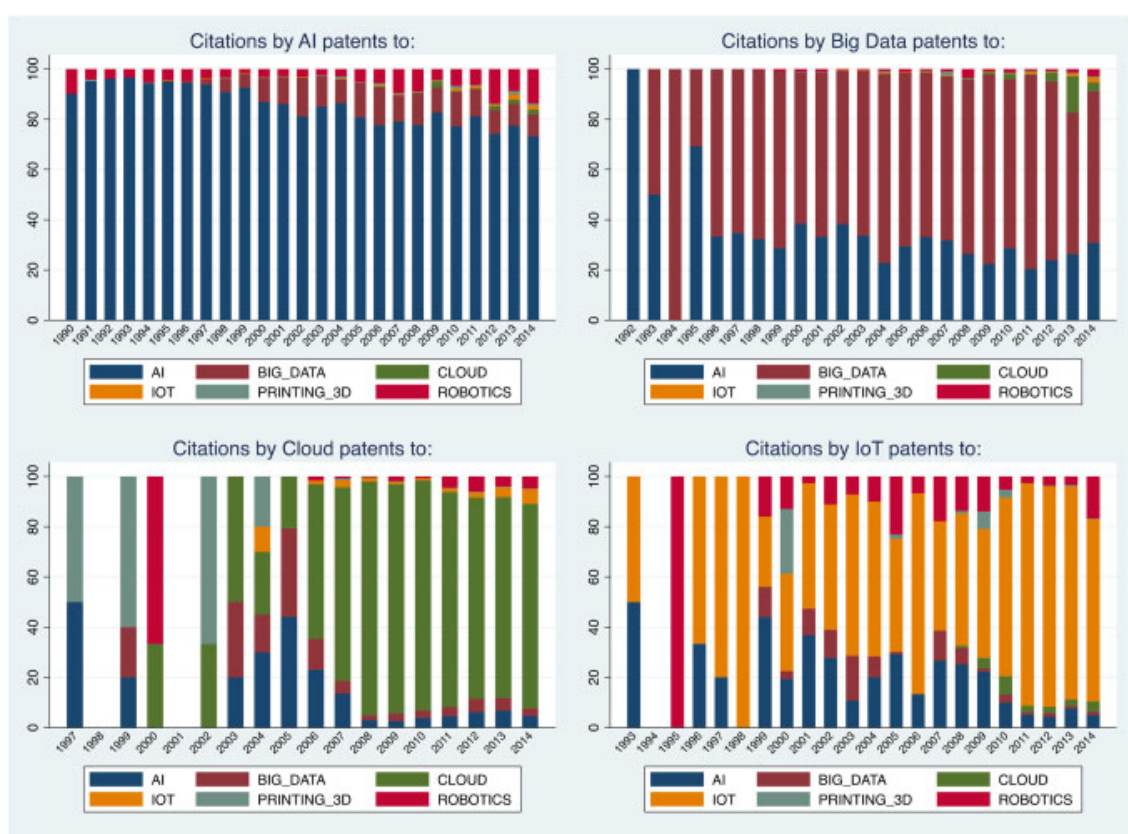

Citations by 3D Printing patents to:
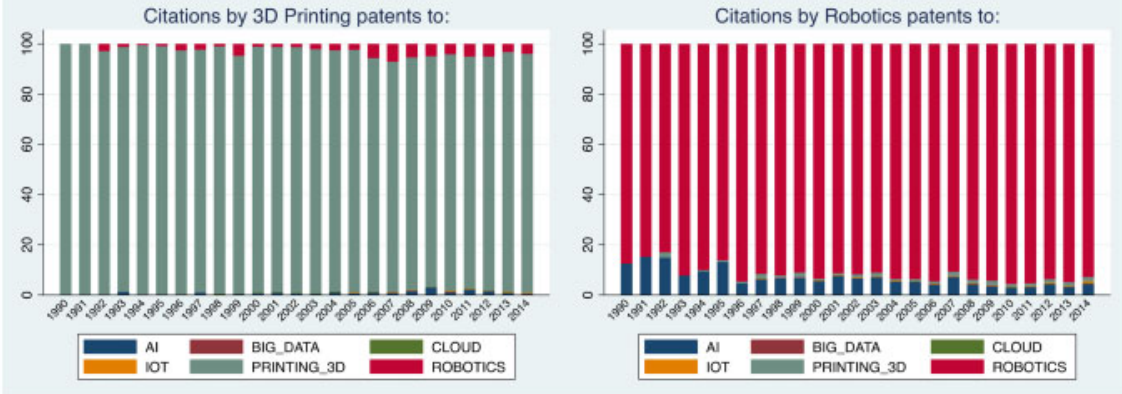

Figure 8. Distribution of cited patents between enabling technologies.

patents related to Industry 4.0 are significantly less original and general than their controls. Conversely, patents related to Industry 4.0 are cited over longer periods, receive more citations in the 5 years after the application, and have a broader scope than the control patents.

To confirm whether the difference in the generality indicator persists while controlling for patent characteristics, we run a regression exercise. Table 7 reports three sets of results for different models' specifications and the three dependent variables (i.e. generality, originality, and average longevity). The main variable of interest is the dummy variable INDUSTRY_4_0, which takes value one if the patent is related to one of the six enabling technologies under examination, and zero if the patent is a matched control. The first three columns of each table panel present the results for the whole sample, while the last three focus on the subsample of patents whose dependent variable is above the sample median. The top panel presents the results for GENERALITY where the dummy INDUSTRY_4_0 is always negative and significant, indicating that the patents in our sample are significantly less general than a comparable sample. The middle panel presents similar results for ORIGINALITY, where the dummy INDUSTRY_4_0 is either negative or insignificant. Finally, the bottom panel shows the results for AV_LONGEVITY, which confirms the finding of Table 6. The dummy INDUSTRY_4_O is always positive and significant, indicating that the patents in our sample are cited significantly longer than a comparable sample. All in all, even though these results are not clear cut, they provide some indication that the technologies under examination are not yet a GPT relative to comparable technologies. 


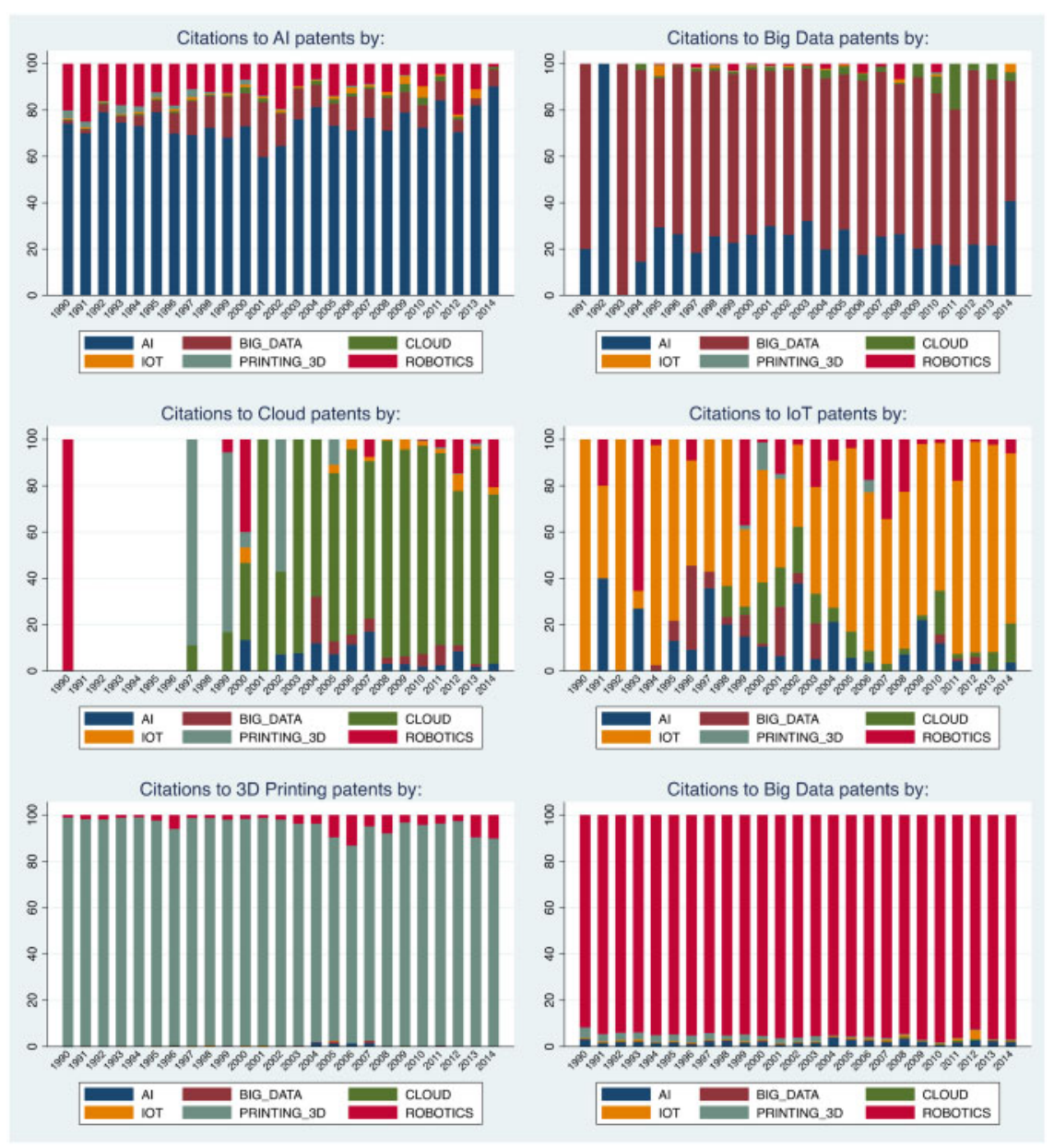

Figure 9. Distribution of citing patents between enabling technologies.

Table 6 -Mann-Whitney test

Variable

H0: Industry_4_0 = Control

ORIGINALITY

GENERALITY

AV_LONGEVITY_Y

$M A X \_L O N G E V I T Y \_Y$

$54.178^{* * n+20}$

$3.214^{* * * *}$

$-27.926^{* * *}$

FORW_CIT_5Y

NUM_CLASS

$-28.652^{* * * *}$

$-51.332^{* * * *}$

$-44.721^{* * * *}$

*** Statistically significant at the $1 \%$.

Following these results, we run the same regressions on each technology group. Figure 10 reports these results together with the estimate of the INDUSTRY_4_0 effect for the pooled sample. ${ }^{9}$ Figure 10(a) displays all the estimates for the technology dummy, indicating that for all technologies, except for Big Data, the patents are not more general than the matched controls. Also Figure 10(b) displays some heterogeneity, indicating that only 
Table 7 -Regression results

\section{DV: GENERALITY}

\begin{tabular}{|c|c|c|c|c|c|c|}
\hline & \multicolumn{3}{|c|}{ FULL SAMPLE } & \multicolumn{3}{|c|}{ GENERALITY ABOVE THE MEDIAN } \\
\hline & (1) & $(2)$ & (3) & (4) & $(5)$ & (6) \\
\hline FORW_CIT_5Y & & $\begin{array}{c}-0.001^{* * * * *} \\
(0.00)\end{array}$ & $\begin{array}{c}-0.001^{\text {w.*n }} \\
(0.00)\end{array}$ & & $\begin{array}{c}-0.003^{* * * * *} \\
(0.00)\end{array}$ & $\begin{array}{c}-0.003^{* \ldots * * *} \\
(0.00)\end{array}$ \\
\hline NUM_CLAIMS & & $\begin{array}{c}-0.000^{\text {w.*n* }} \\
(0.00)\end{array}$ & $\begin{array}{c}-0.000^{\text {w.*n }} \\
(0.00)\end{array}$ & & $\begin{array}{c}-0.001^{* * * *} \\
(0.00)\end{array}$ & $\begin{array}{c}-0.001^{* . * n *} \\
(0.00)\end{array}$ \\
\hline Constant & $\begin{array}{c}0.092^{* * * *} \\
(0.00)\end{array}$ & $\begin{array}{c}0.111^{* * * * *} \\
(0.00)\end{array}$ & $\begin{array}{c}0.119^{m+\ldots * w} \\
(0.00)\end{array}$ & $\begin{array}{c}0.142^{*+* * *} \\
(0.00)\end{array}$ & $\begin{array}{c}0.175^{* * n} \\
(0.00)\end{array}$ & $\begin{array}{c}0.227^{m+n} \\
(0.00)\end{array}$ \\
\hline YEAR DUMMY & YES & YES & NO & YES & YES & YES \\
\hline \multicolumn{7}{|l|}{ DV: ORIGINALITY } \\
\hline & \multicolumn{3}{|c|}{ FULL SAMPLE } & \multicolumn{3}{|c|}{ ORIGINALITY ABOVE THE MEDIAN } \\
\hline & $(1)$ & $(2)$ & (3) & $(4)$ & $(5)$ & $(6)$ \\
\hline INDUSTRY_4_0 & $\begin{array}{c}-0.018^{* * * *} \\
(0.00)\end{array}$ & $\begin{array}{c}-0.011^{w * * * *} \\
(0.00)\end{array}$ & $\begin{array}{c}-0.011^{* * * *} \\
(0.00)\end{array}$ & $\begin{array}{c}-0.004^{* * * *} \\
(0.00)\end{array}$ & $\begin{array}{l}0.000 \\
(0.00)\end{array}$ & $\begin{array}{c}-0.001 \\
(0.00)\end{array}$ \\
\hline FORW_CIT_5Y & & $\begin{array}{c}-0.000^{* * * * *} \\
(0.00)\end{array}$ & $\begin{array}{c}-0.001^{* \ldots * k} \\
(0.00)\end{array}$ & & $\begin{array}{c}-0.001^{* * * *} \\
(0.00)\end{array}$ & $\begin{array}{c}-0.001^{* \ldots * n} \\
(0.00)\end{array}$ \\
\hline NUM_CLASS & & $\begin{array}{c}-0.006^{* * * *} \\
(0.00)\end{array}$ & $\begin{array}{c}-0.005^{\omega * \ldots *} \\
(0.00)\end{array}$ & & $\begin{array}{c}-0.008^{* * * * *} \\
(0.00)\end{array}$ & $\begin{array}{c}-0.007^{* \ldots+*} \\
(0.00)\end{array}$ \\
\hline NUM_CLAIMS & & $\begin{array}{c}-0.000^{k+n} \\
(0.00)\end{array}$ & $\begin{array}{c}-0.001^{* * *} \\
(0.00)\end{array}$ & & $\begin{array}{c}-0.000^{* * * *} \\
(0.00)\end{array}$ & $\begin{array}{c}-0.001^{\text {(⿻一未 }} \\
(0.00)\end{array}$ \\
\hline \multicolumn{7}{|l|}{ DV: LONGEVITY } \\
\hline & \multicolumn{3}{|c|}{ FULL SAMPLE } & \multicolumn{3}{|c|}{ LONGEVITY ABOVE THE MEDIAN } \\
\hline & $(1)$ & (2) & (3) & (4) & $(5)$ & (6) \\
\hline INDUSTRY_4_0 & $\begin{array}{c}0.479^{\text {\#n }} \\
(0.01)\end{array}$ & $\begin{array}{c}0.428^{\text {*n \# }} \\
(0.01)\end{array}$ & $\begin{array}{c}0.440^{\text {*n }} \\
(0.01)\end{array}$ & $\begin{array}{c}0.263^{* * * x} \\
(0.02)\end{array}$ & $\begin{array}{c}0.314^{\text {n+n }} \\
(0.02)\end{array}$ & $\begin{array}{c}0.344^{\text {wn+w }} \\
(0.02)\end{array}$ \\
\hline FORW_CIT_5Y & & $\begin{array}{c}0.030^{* n *} \\
(0.00)\end{array}$ & $\begin{array}{c}0.027^{* \ldots *} \\
(0.00)\end{array}$ & & $\begin{array}{c}-0.026^{* * * *} \\
(0.00)\end{array}$ & $\begin{array}{c}-0.031^{\text {n. }} \\
(0.00)\end{array}$ \\
\hline NUM_CLASS & & $\begin{array}{c}-0.036^{* \ldots * *} \\
(0.00)\end{array}$ & $\begin{array}{c}-0.020^{* \ldots * *} \\
(0.00)\end{array}$ & & $\begin{array}{c}-0.007^{* * * *} \\
(0.00)\end{array}$ & $\begin{array}{c}-0.003 \\
(0.00)\end{array}$ \\
\hline NUM_CLAIMS & & $\begin{array}{c}0.022^{n+m * x} \\
(0.00)\end{array}$ & $\begin{array}{c}0.013^{* n+\infty} \\
(0.00)\end{array}$ & & $\begin{array}{c}0.002^{*+* w} \\
(0.00)\end{array}$ & $\begin{array}{c}0.004^{*+n} \\
(0.00)\end{array}$ \\
\hline Constant & $\begin{array}{c}11.585^{* * * *} \\
(0.08)\end{array}$ & $\begin{array}{c}11.294^{3 * \text { th }} \\
(0.08)\end{array}$ & $\begin{array}{c}3.778^{* n+k} \\
(0.01)\end{array}$ & $\begin{array}{c}12.247^{\text {*n w }} \\
(0.07)\end{array}$ & $\begin{array}{c}12.357^{* \ldots \times} \\
(0.07)\end{array}$ & $\begin{array}{c}7.678^{*+* 6} \\
(0.01)\end{array}$ \\
\hline YEAR DUMMY & YES & YES & NO & YES & YES & YES \\
\hline MATCHED GROUP FIXED EFFECT & NO & NO & YES & NO & NO & NO \\
\hline Observations & 323652 & 323652 & 323652 & 157802 & 157802 & 157802 \\
\hline $\mathrm{R}^{2}$ & 0.608 & 0.617 & 0.729 & 0.520 & 0.526 & 0.657 \\
\hline
\end{tabular}

Note: All the models are estimated using Ordinary Least Square. Robust standard errors in brackets.

* Significant at $10 \%$.

* Significant at $5 \%$.

$* * *$ Significant at $1 \%$. 
(a)

Dependent variable: Generality

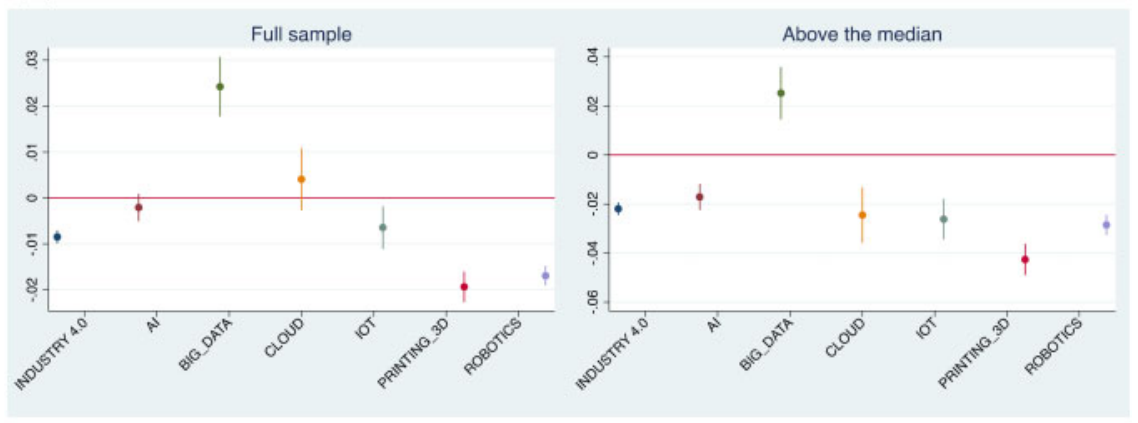

(b)

Dependent variable: Originality

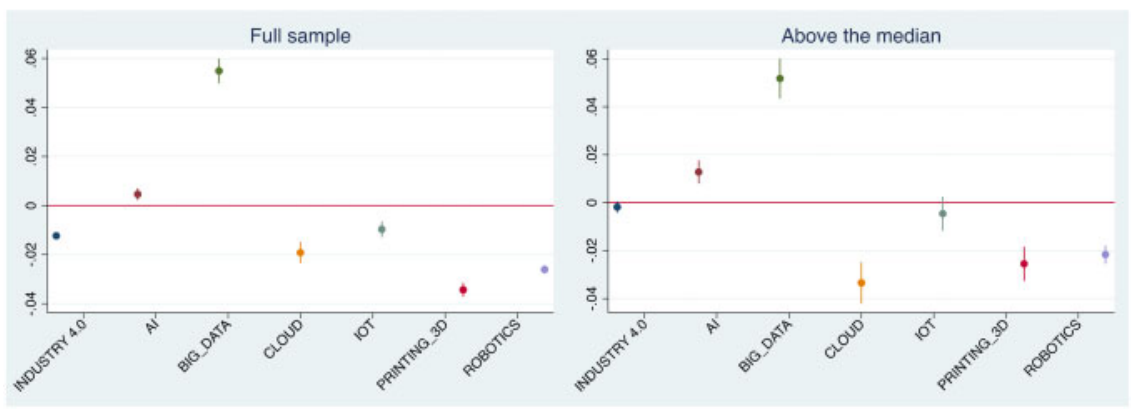

(c)

Dependent variable: Average Longevity

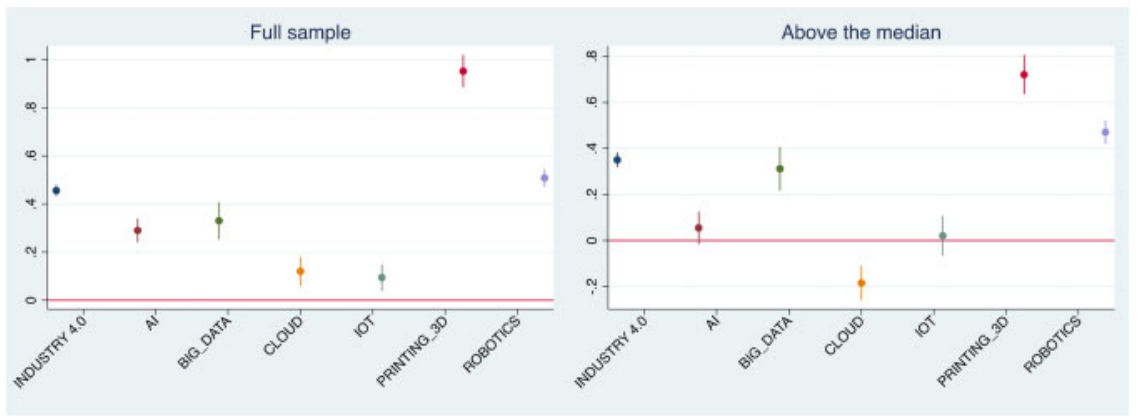

Figure 10. Regression results for the split sample analysis for each technology.

AI and Big Data are more original than the matched controls. Finally, Figure 10(c) shows that all the technologies included in our sample are cited for longer timespans than the controls. However, when we focus the analysis on the longest-lived patents-the results on the patents whose longevity is above the median, some differences emerge. Patents related to Cloud technologies display lower longevity than the controls. This difference is statistically significant, while there is no statistically significant difference for AI and IoT relative to the counterfactuals.

Taken together, these results have at least two interesting implications. First, they confirm the existence of significant heterogeneity between the technologies under investigation. Second, only Big Data and to a lesser extent AI show the characteristics of a distinctive GPT in terms of generality and originality, whereas the other technologies under examination are better framed-at least at this point in time-as enabling technologies rather than GPTs, despite the strong longevity performance recorded across the board (especially for 3D printing). There are two 
caveats. The first is that these enabling technologies might well develop into GPTs in the future jointly or individually. ${ }^{10}$ The second is that the test we have applied is strict in the identification of the control group, which is drawn from the same primary patent class as the focal sample. The results should therefore be interpreted as evidence that - with the exceptions of Big Data and AI—there is no strong indication across the board that these technologies are as yet a dramatic departure from the ICT paradigm in which they operate.

\section{Drivers of industrial change: a discussion and research agenda}

There are several relatively unexplored aspects of I4.0 enabling technologies, whose study presents some of the problems typically posed by emergent technologies (including fluid boundaries and definitions, as well as uncertainty in their patterns of development). We believe that there are (at least) four sets of problems that need to be addressed to gain better understanding of these enabling technologies and monitor their possible transformation in the GPTs of a Fourth Industrial Revolution. These problems are: adoption, industrial dynamics, standards, and government policy.

\subsection{Technology adoption}

One of the problems faced in empirical research on new digital technologies is the lack of systematic microdata on adoption. This is clearly a major drawback considering that the revolutionary potential of new technologies resides in their use, diffusion and adaptation. Overall, the diffusion of Industry 4.0 appears to be uneven across sectors and countries. Market reports suggest high sales growth in IoT and additive manufacturing, and slower growth in robots (a more mature segment) and advanced human-machine interfaces (a possible sign of the aforementioned difficulty to apply AI effectively to current production processes). ${ }^{11}$ However, it is very difficult to produce a robust comparative analysis of firm adoption decisions without suitable official data, and it is equally difficult to study their effects without longitudinal data even when some cross-sectional data are available.

The context of application also matters. Germany is at the frontier of Industry 4.0 and emergent evidence of adoption in this country provides very useful insights. A recent study of 128 adoption cases across 500 production sites (IoT Analytics, 2016) uncovered a clear dichotomy between large companies, which are the most advanced buyers and lead users, and small and medium sized firms, which are lagging behind, suggesting cost and absorptive capacity barriers to adoption. Moreover, the majority of firms seem to have privileged "single technologies" adoption paths while only few companies are undertaking a systemic (multi-technology) approach. Italy provides interesting contrasting evidence: despite the role played by the manufacturing sector in the structure of its economy (including exports), it is a context where the process of diffusion of "pre-smart" technologies (e.g. CAD/CAE/CAM) has not yet been completed and the adoption of "smart" technologies started significantly later than in Germany. A survey of 23,000 companies recently carried out by the Italian Ministry of Industry and Economic Development (Ministero dello Sviluppo Economico, 2018) illustrates the very slow uptake of Industry 4.0 technologies: only $8.4 \%$ of manufacturing companies (most of which large) have made investments in this space, and only $4.7 \%$ intend to do so in the next 3 years, against estimates that show positive returns to adoption. As in the German case, firms that adopt a multi-technology approach are a minority. The same data indicate as main drivers of adoption increased competitiveness through greater production efficiency (e.g. due to cost optimization and greater flexibility), and product quality improvement through minimization of production errors. Further research should therefore focus not only on adoption choices but also on the practice of adoption and the adaptation of these technologies to specific contexts of production.

\subsection{Industrial dynamics}

The six enabling technologies display different industrial and market dynamics. If we consider the IoT segment, sensors producers and telecom providers are capable of covering only their core area of specialization, and at present neither have strong competences in machine and processes nor ownership of the data produced. Competition seems

10 Note that regression analysis run over the six period we previously used (see Table 2) shows that these results are consistent over the period under examination.

11 Regarding the geographical distribution of 14.0 , it is interesting to notice in the figures for robotics that China is the largest adopter by absolute numbers, while South Korea, Japan, and Germany are leading by intensity of adoption. 
to be driven by machine producers, lead users, and software companies. A particular challenge is the ongoing competition between proprietary vs. open source architectures. Additive manufacturing and robotics markets are relatively more mature. Additive manufacturing is strongly segmented in two different compartments (business and consumers) with different technologies and players. However, despite high barrier to entry in both segments, and also despite the fact that both segments depend on the quality of extruding technologies (this determines printing quality), the sector is still decisively unstable: after the expiration of key patents in 2014-2015, new industrial research has marked the entry of traditional printer players (such as HP), services players (such as Amazon), or software players (such as Autodesk), which could radically change the competitive landscape. Robotics has instead received new impulse by the aggressive entry of Chinese producers as well as the introduction of new materials, and advances in AI and its latest applications to human-machine interfaces. In turn, these are directly related to fast progress in big data and manufacturing analytics. Big data analytics features some of the major ICT players such as IBM (U.S.), General Electric (U.S.), Microsoft (U.S.), Oracle (U.S.), PTC Inc. (U.S.), SAP SE (Germany), Cisco (U.S.), Hewlett Packard (U.S), Hitachi (Japan), and SAS (U.S.). Interestingly, most large organizations in North America are choosing on-cloud deployment because of cheaper installation and ease of data retrieval (anytime, anywhere). Cloud computing is itself fragmented in Infrastructure-as-a-Service (IaaS), Platform-as-a-Service (PaaS), and Software-as-a-Service (SaaS) markets, depending on the degree of outsourcing. Moving from the former to the latter, there is an increasing level of efficiency (in terms of cost reduction), but also less control over data and software (the customer would typically deploy its own software on the infrastructure and platform). The three tiers are also characterized by different barrier to entry: SaaS has the lowest and new entrants can take advantage of low required initial investment and quick time to market (Catinean, 2013). For PaaS, in-house development and human capital constitute significant barriers, while IaaS requires substantial financial investment in order to build and support the Cloud infrastructure.

Overall, the patterns of entry and industry growth differ within and across sectors, and some of the key segments presents the typical turbulence of fluid phases of technology life cycles. The presence of large players (e.g. Google, IBM) in related segments and related enabling technologies could, however, limit entry by small innovative firms and provide scope for agglomeration and diversification strategies.

\subsection{Industry standards}

One of the most interesting areas for research, with implications for both industrial dynamics and the diffusion of I4.0 enabling technologies, is the problem of standards. Of paramount importance are legal standards for robotics and AI, and technical standards for the most highly networked technical systems, such as IoT and Cloud. The lack of standards is one of the most serious barriers to adoption. Beside the ethical issues of robotics and AI regulation, at the technology level the clearest tension is between the push for proprietary standards by early-stage global players, and the preference of adopters' consortia for more open standards (such as the RAMI 4.0 architecture elaborated by "Platform Industrie 4.0" and the IIRA of the Industrial Internet Consortium).

Standards allows interoperability in complex technical systems and this is precisely the problem faced by the IoT industry, where companies are joining different consortia and entering different alliances in order to generate the critical mass needed for the generation of voluntary de facto standards [among them, Auto-ID Lab and the Alliance for the Internet of Things Innovation (AIOTI), promoted by the European Commission]. Other parts of the systems are under the control to standard setting bodies: RFID technologies, frequency and the format of data are under the remit of GS1, the European Telecommunications Standards Institute (ETSI) and ISO (Atzori et al., 2010). ${ }^{12}$ The definition of standards is also related to broader regulatory issues. Firstly, competition, given the need to address new markets and their boundaries. Secondly, privacy, given the sensitive nature of the type of data smart objects will be able to gather. ${ }^{13}$ Thirdly, cyber security: as noted by Whitmore (2015), current approaches to cyber-security, mostly based on encryption, may not be feasible for smart objects with limited computing capabilities. Cloud is another domain strongly affected by the availability of standards or lack thereof. Cloud interoperability is a major issue (Dillon 2010), but there is no agreement of how best to address the problem. For example, IBM subscribed to the Open Cloud Manifesto (2009), but Microsoft and Amazon did not. Parallel standardization initiatives are proliferating, led

12 For the broader loT architecture, ETSI is also play a role through its Machine-to-Machine Technical Committee.

13 As noted by Weber (2011), there will be a need for extreme transparency in tracing the flows and type of data transmitted. 
both by businesses alliances and by the main international standard-setting organizations (e.g. ISO, IEEE, and the ITU). ${ }^{14}$ Moreover, the European Commission has specifically identified IoT and Cloud, together with cybersecurity and $5 \mathrm{G}$ communications as essential technology building blocks of the Digital Single Market. ${ }^{15}$ In summary, (interrelated) standards races and de jure standardization processes will play a fundamental role in shaping the competitive environment, but whether these processes will follow the same lines of development of previous ITC standard making experiences remains an open question. At the moment, the technical and legal complexities of the problem, appear to be very distinctive of this phase of industrial growth and will deserve careful study.

\subsection{Government policy}

Enabling technologies are fast becoming a central part of a new wave of industrial policies, many of which are specifically designed to foster the development and diffusion of Industry 4.0. The IPOL Study Group on Industry 4.0 (European Parliament, 2016) describes a series of interventions that can be classified as:

- integrated adoption processes and a strong cooperation between industry, trade unions and companies;

- more targeted approaches focusing on individual technologies;

- "neutral" direct approaches (firms use subsidies but select their technology of choice);

- "neutral" indirect approaches (more standard tax incentives).

Very often different policies coexist within the same country more or less coherently, and more or less related to a "mission-oriented" approach to science and technology policy, or industrial policy more broadly. It is not clear which type of policy and which policy mixes will prove effective in supporting the competitiveness of different economies, especially if we consider that the same interventions may produce very different effects on systems that are structurally different in their production and application of I4.0 enabling technologies. This is an essential area for further research, not least because this level of policy intervention is related to other policy domain (above all labor policy) directly called into question by the revolutionary nature of emergent GPTs.

\section{Conclusion}

Industry 4.0 is a complex and heterogonous cluster of emergent technologies that contains the seeds of the Fourth Industrial Revolution. From the viewpoint of broad technological backgrounds, semiconductor and internet technologies, increasingly rich in AI content, are overall predominant components of Industry 4.0 systems. Given the information technology roots of these domains, it can be argued that so far we have been observing the continuation, or perhaps amplification, of the Third Industrial Revolution, rather than the clear-cut birth of a Fourth. In this article, we have identified and examined in some detail the six main components of the new digital economy grown out of the established semiconductor-cum-internet paradigm. While we cannot make simple predictions on future technological developments, at the time of writing, the two technology groups that give the strongest indication of becoming distinctive GPTs are Big Data and AI.

It is important to remember that many of the building blocks of Industry 4.0 have long historical roots: robotics and human-machine interfaces are based on the existing mechatronic industry; the use of sensors in machines has more than 20 years of history, and so do machines connected to computers; 3D printing is now more than 30 years old and even AI has been around for many years but only now it is beginning to have a visible impact on businesses. The introduction of complementary and incremental innovations are changing the potential application of known techniques: the introduction of low energy consumption in sensors, and their declining costs, are boosting their diffusion; advanced machine learning and deep learning are now beginning to drive automation; the introduction of cloud connectivity is delivering low cost processing power and pervasive interconnection; and finally, new ways to connect monitoring and management systems (the so-called "digital twins"). In this article, we have provided an in-depth analysis of the technological characteristics of new enabling technologies. Much work remains to be done not only

14 The European Commission is considering $5 \mathrm{G}$ communications, Cloud, loT, (big) data technologies, and cybersecurity as essential technology building blocks of the Digital Single Market. 
on the drivers of structural change, but—ultimately—on the long-term effects of these technologies on growth, productivity, and employment.

\section{Acknowledgments}

The authors are most grateful to Giovanni Dosi, Aldo Geuna, Marco Guerzoni, Martina Iori, Giorgio Tripodi, Pietro Bonaccorsi, Damiano Morando, Matteo Tranchero, Lorenzo Spadavecchia, and the discussants and participants of the RENIR Workshop 2019 at Collegio Carlo Alberto, University of Turin, and the EMAEE 2019 Conference at SPRU, University of Sussex. The comments and constructive criticisms of the Guest Editors and two anonymous referees are also gratefully acknowledged. This article is produced as part of the GROWINPRO project on Growth Welfare Innovation Productivity that has received funding from the European Union Horizon 2020 research and innovation programme under grant agreement No. 822781.

\section{References}

Acemoglu, D. and P. Restrepo (2017), 'Robots and jobs: evidence from US labor markets,' NBER, Working Paper No. 23285.

Adamson, G., L. Wang and M. Holm (2013), 'The state of the art of cloud manufacturing and future trends,' 2013 International Manufacturing Science and Engineering Conference collocated with the 41st North American Manufacturing Research Conference, Vol. 2. Systems; Micro and Nano Technologies; Sustainable Manufacturing Madison: Madison, WI, June 10-14.

Ardito, L., D. D’Adda and A. Messeni Petruzzelli (2018), 'Mapping innovation dynamics in the Internet of Things domain: evidence from patent analysis,' Technological Forecasting and Social Change, 136, 317-330.

Atzori, L., A. Iera and G. Morabito (2010), 'The Internet of Things: a survey,' Computer Networks, 54(15), $2787-2805$.

Benrachi-Maassam, S. (2012), Lessons learned from early M2M developments,' in D. Boswarthick, O. Elloumi, O. Hersent (eds), M2M Communications: A Systems Approach. Hoboken, NJ: Wiley, pp. 57-71.

@Breschi, S., F. Malerba and L. Orsenigo (2000), 'Technological regimes and Schumpeterian patterns of innovation,' Economic Journal, 110(463), 388-410.

@Bresnahan, T. F. and M. Trajtenberg (1995), 'General purpose technologies 'Engines of growth'?,' Journal of Econometrics, 65(1), 83-108.

Bresnahan, T. (2010), 'General purpose technologies,' in B. H. Hall and N. Rosenberg (eds) Handbook of the Economics of Innovation, Vol. 2. Elsevier, pp. 761-791.

Bughin, J., E. Hazan, S. Ramaswamy, M. Chui, T. Allas, P. Dahlström, N. Henke and M. Trench (2017), Artificial Intelligence: The Next Digital Frontier? McKinsey Global Institute, Discussion Paper, June.

Bughin, J., J. Seong, J. Manyika, M. Chui and R. Joshi (2018), Notes from the AI Frontier: Modeling the Impact of AI on the World Economy. McKinsey Global Institute, Discussion Paper, September 2018.

Caldarelli, A., L. Ferri and M. Maffei (2017), 'Expected benefits and perceived risks of cloud computing: an investigation within an Italian setting,' Technology Analysis \& Strategic Management, 29 (2), 167-180.

@Chopra, S. and M. S. Sodhi (2007), 'Looking for the bang from the RFID buck,' Supply Chain Management Review, 11 (4), 34-41.

Christensen, C. M. (1997), The Innovator's Dilemma. Cambridge: Harvard Business School Press.

Commission of the European Communities (2009), 'Preparing for Our Future: Developing a Common Strategy for Key Enabling Technologies in the EU,' Document 52009DC0512.

Dotsika, F. and A. Watkins (2017), 'Identifying potentially disruptive trends by means of keyword network analysis,' Technological Forecasting and Social Change, 119, 114-127.

Dosi, G. (1982), 'Technological paradigms and technological trajectories: a suggested interpretation of the determinants and directions of technical change,' Research Policy, 11 (3), 147-162.

@Dosi, G. (1988), 'Sources, procedures and microeconomic effects of innovation,' Journal of Economic Literature, 26, $120-1171$.

European Commission (2017), 'Horizon 2020 Work Program 2018-2020 Part 5: Leadership in Enabling and Industrial Technologies. European Commission Decision C(2017) 7124 of 27 October 2017,' https://ec.europa.eu/programmes/horizon2020/sites/hori zon2020/files/h2020-wp1820-leit_en.pdf.

PFrey, C. B. and M. A. Osborne (2017), 'The future of employment: how susceptible are jobs to computerisation?,' Technological Forecasting and Social Change, 114, 254-280.

Hall, B. H. and M. Trajtenberg (2004), "Uncovering GPTS with patent data,” NBER Working Papers, No. 10901, National Bureau of Economic Research, Inc., www.nber.org/papers/w10901.

Hashem, I. A. T., I. Yaqoob, N. B. Anuar, S. Mokhtar, A. Gani and S. U. Khan (2015), 'The rise of "big data” on cloud computing: review and open research issues,' Information Systems, 47, 98-115.

Helpman, E. (ed.) (1998), General Purpose Technologies and Economic Growth. Cambridge, MA: MIT Press.

Huang, J. (2016), 'Patent portfolio analysis of the cloud computing industry,' Journal of Engineering and Technology Management, $39,45-64$. 
Majhi, S. K. and G. Shial (2015), 'Challenges in big data cloud Computing and Future Research Prospects: a Review,' The Smart Computing Review, 5(4), 340-345.

@Jaffe, A. (1986), 'Technological opportunity and spillovers of R\&D: evidence from firms' patents, profits, and market value,' American Economic Review, 76, 985-1001.

@Jaffe A. (1989), 'Characterizing the 'technological position' of firms, with application to quantifying technological opportunity and research spillovers,' Research Policy, 18(2), 87-97.

Kagermann, H., W. Wahlster and J. Helbig (2013), 'Securing the Future of German Manufacturing Industry: Recommendations for Implementing the Strategic Initiative INDUSTRIE 4.0,' Final Report of the Industrie 4.0 Working Group http://alvarestech.com/ temp/tcn/CyberPhysicalSystems-Industrial4-0.pdf.

IDC (2018), 'Worldwide Semiannual Artificial Intelligence Systems Spending Guide,' https://www.idc.com/getdoc.jsp? containerId= IDC_P33198.

IFR (2017), 'World Robotics 2016 Industrial Robots Report,' https://ifr.org/img/uploads/Executive_Summary_WR_Industrial_ Robots_20161.pdf.

IoT Analytics (2015), 'IoT Market Analysis: Sizing the Opportunity,' http://iot-analytics.com/wp/wp-content/uploads/2015/03/2015March-Whitepaper-IoT-Market-analysis-Sizing-the-opportunity.pdf.

Jovanovic, B. and P. L. Rousseau (2005), General Purpose Technologies, in P., Aghion and S., Durlauf (eds) Handbook of Economic Growth, Vol. 1, Part B. Amsterdam: Elsevier. pp. 1181-1224.

PKim, D., H. Lee and J. Kwak (2017), 'Standards as a driving force that influences emerging technological trajectories in the converging world of the Internet and things: an investigation of the M2M/IoT patent network,' Research Policy, 46(7), 1234-1254.

Kubac, L., V. Benes, F. Kebo and P. Stasa (2013), 'RFID and augmented reality,' Proceedings of the 14th International Conference on Carpathian Control (ICCC). pp. 186-191.

@Lee, J., H. Davari, J. Singh and V. Pandhare (2018), 'Industrial artificial intelligence for industry 4.0-based manufacturing systems,' Manufacturing Letters, 18, 20-23.

PLiu, C. M. and L. S. Chen (2009), 'Applications of RFID technology for improving production efficiency in an integrated-circuit packaging house,' International Journal of Production Research, 47 (8), 2203-2216.

@Malerba, F. and L. Orsenigo (1996a), 'The dynamics and evolution of industries,' Industrial and Corporate Changes, 5(1), 51-87.

@Malerba, F. and L. Orsenigo (1996b), 'Schumpeterian patterns of innovation are technology specific,' Research Policy, 25(3), $451-478$.

@Malerba, F. and L. Orsenigo (1997), 'Technological regimes and sectoral patterns of innovative avtivities,' Industrial and Corporate Change, 6(1), 83-118.

Ministero dello Sviluppo Economico (2018), 'La Diffusione delle Imprese 4.0 e le Politiche: Evidenze 2017,' http://www.industriequat tropuntozero.it/files/2018/07/Rapporto-MiSE-MetI40.pdf.

PMoser, P. and T. Nicholas (2004), 'Was electricity a general purpose technology? Evidence from historical patent citations,' American Economic Review, 94 (2), 388-394.

Nilsson, N. (2010), The Quest for Artificial Intelligence: A History of Ideas and Achievements. Cambridge: Cambridge University Press.

Rosenberg, N. (1982), Inside the Black Box: Technology and Economics. Cambridge (UK) and New York: Cambridge University Press.

Rosenberg, N. (1994), Exploring the Black Box: Technology, Economics and History. Cambridge (UK) and New York: Cambridge University Press.

Squicciarini, M., H. Dernis and C. Criscuolo. (2013), 'Measuring patent quality: indicators of technological and economic value', OECD Science, Technology and Industry Working Papers, 2013/03, OECD Publishing. http://doi.org/10.1787/5k4522wkw1r8en.

Tao, F. Y., L. D. Cheng, L. Xu and B. H. Li Zhang (2014), 'CCIoT-CMfg: Cloud Computing and Internet of Things Based Cloud Manufacturing Service System,' IEEE Transactions on Industrial Informatics, 10(2), 1435-1442.

PTeece D. (2018), 'Profiting from innovation in the digital economy: enabling technologies, standards, and licensing models in the wireless world,' Research Policy, 47(8), 1367-1387.

PTrajtenberg, M., A. Jaffe and R. Henderson (1997), 'University versus corporate patents: a window on the basicness of inventions,' Economics of Innovation and New Technology, 5(1), 19-50.

@Tushman, M. L. and P. Anderson (1986), 'Technological discontinuities and organisational environments,' Administrative Science Quarterly, 31(3), 439-465.

UK IP Office (2013), ‘3D printing: a patent overview, UK Intellectual Property (IP) Office,' https://assets.publishing.service.gov.uk/ government/uploads/system/uploads/attachment_data/file/445232/3D_Printing_Report.pdf.

UK IP Office (2014), 'Big Data, UK Intellectual Property (IP) Office,' https://assets.publishing.service.gov.uk/government/uploads/sys tem/uploads/attachment_data/file/325024/informatics-bigdata.pdf. 
UK IP Office (2014), 'Eight Great Technologies: Robotics and Autonomous Systems, UK Intellectual Property (IP) Office,' https:// assets.publishing.service.gov.uk/government/uploads/system/uploads/attachment_data/file/318236/Robotics_Autonomous.pdf.

Van Looy, B., C. Vereyen and U. Schmoch (2015), 'Patent Statistics: Concordance IPC V8 - NACE Rev. 2 (version 2.0)', Eurostat Working Paper. https://circabc.europa.eu/d/d/workspace/SpacesStore/d1475596-1568-408a-9191-426629047e31/2014-10-16Final\%20IPC_NACE2_2014.pdf.

Webb, C., H. Dernis, D. Harhoff and K. Hoisl (2005), 'Analysing European and International Patent Citations: a Set of EPO Patent Database Building Blocks', STI Working Paper 2005/9, OECD: Paris.

Webb, N. S., N. Bloom and J. Lerner (2018), 'Some Facts of High-Tech Patenting', NBER Working Paper 24793.

Wei, C. M., C. L. Zhang, T. X. Song and B. Q. Huang (2013), A Cloud Manufacturing Service Management Model and Its Implementation,' Proceedings of IEEE International Conference in Service Sciences (ICSS). pp. 60-63.

Wu, D., D. W. Rosen, L. Wang and D. Schaefer (2015), 'Cloud-based design and manufacturing: a new paradigm in digital manufacturing and design innovation,' Computer-Aided Design, 59, 1-14.

Wu, D., M. J. Greer, D. W. Rosen and D. Schaefer (2013), 'Cloud manufacturing: strategic vision and state-of-the-art,' Journal of Manufacturing Systems, 32 (4), 564-579.

PYang, Z. M., D. Djurdjanovic and J. Ni (2008), 'Maintenance scheduling in manufacturing systems based on predicted machine degradation,' Journal of Intelligent Manufacturing, 19(1), 87-98.

@Zhang, Y., T. Qu, O. K. Ho and G. Q. Huang (2011), 'Agent-based smart gateway for RFID-enabled real-time wireless manufacturing,' International Journal of Production Research, 49(5), 1337-1352. 


\section{Appendix A}

Table A1 -Descriptive statistics of the focal and control samples

Patents related to industry 4.0

\begin{tabular}{|c|c|c|c|c|c|c|}
\hline Variable & Obs & Mean & Median & SD & Min & $\operatorname{Max}$ \\
\hline ORIGINALITY & 54,109 & 0.0891 & 0.055 & 0.115 & 0 & 1 \\
\hline GENERALITY & 54,109 & 0.0869 & 0.0449 & 0.138 & 0 & 1 \\
\hline AVERAGE_LONGEVITY & 54,109 & 4.49 & 3.5 & 4.38 & 0 & 26.5 \\
\hline MAX_LONGEVITY & 54,109 & 6.85 & 5 & 7.14 & 0 & 29 \\
\hline FORW_CIT_5Y & 54,109 & 4.56 & 2 & 13.5 & 0 & 401 \\
\hline NUM_CLASS & 54,109 & 4.8 & 4 & 4.45 & 1 & 80 \\
\hline \multicolumn{7}{|l|}{ Control patents } \\
\hline Variable & Obs & Mean & Median & SD & Min & $\operatorname{Max}$ \\
\hline ORIGINALITY & 269,543 & 0.107 & 0.07 & 0.127 & 0 & 1 \\
\hline GENERALITY & 269,543 & 0.0999 & 0.0496 & 0.158 & 0 & 1 \\
\hline AVERAGE_LONGEVITY & 269,543 & 4 & 3 & 4.3 & 0 & 28 \\
\hline MAX_LONGEVITY & 269,543 & 6.08 & 4 & 6.99 & 0 & 29 \\
\hline FORW_CIT_5Y & 269,543 & 2.86 & 1 & 7.38 & 0 & 340 \\
\hline NUM_CLASS & 269,543 & 3.91 & 3 & 3.18 & 1 & 113 \\
\hline
\end{tabular}

Table A2 - List of variables and sources

\begin{tabular}{|c|c|c|}
\hline Variable & Description & Source \\
\hline GENERALITY & $\begin{array}{l}\text { 1-HHI }{ }_{p} \text { where } \mathrm{HHI}_{\mathrm{p}} \text { is the Hirschman-Herfindahl } \\
\text { Index of the shares of the IPC classes ( } 8 \text {-digit) of the citing patents } \\
\text { (forward citations) in the first } 5 \text { years after the granting. }\end{array}$ & $\begin{array}{l}\text { Our calculations using the } \\
\text { EPO-PATSTAT Database } \\
\text { (Autumn 2019) }\end{array}$ \\
\hline ORIGINALITY & $\begin{array}{l}\text { 1-HHI }{ }_{p} \text { where } \mathrm{HHI}_{\mathrm{p}} \text { is the Hirschman-Herfindahl } \\
\text { Index of the shares of the IPC classes (8-digit) of the cited patents } \\
\text { (backward citations). }\end{array}$ & \\
\hline AV_LONGEVITY_Y & $\begin{array}{l}\text { Average number of years between the filing of the patent and the } \\
\text { latest forward citation }\end{array}$ & \\
\hline MAX_LONGEVITY_Y & $\begin{array}{l}\text { Maximum number of years between the filing of the patent and the } \\
\text { latest forward citation }\end{array}$ & \\
\hline FORW_CIT_5Y & $\begin{array}{l}\text { Number of citations received by the patents in the } 5 \text { year after the } \\
\text { patent grant }\end{array}$ & \\
\hline NUM_CLASS & Number of distinct 4-digit IPC class listed in the patents & \\
\hline
\end{tabular}

